\title{
Interactions between TrkB Signaling and Serotonin Excess in the Developing Murine Somatosensory Cortex: A Role in Tangential and Radial Organization of Thalamocortical Axons
}

\author{
Tania Vitalis, ${ }^{1}$ Olivier Cases, ${ }^{2}$ Katy Gillies, ${ }^{1}$ Naima Hanoun, ${ }^{3}$ Michel Hamon, ${ }^{3}$ Isabelle Seif, ${ }^{4}$ Patricia Gaspar, ${ }^{2}$ \\ Peter Kind, ${ }^{1}$ and David J. Price ${ }^{1}$ \\ ${ }^{1}$ Department of Biomedical Sciences, University of Edinburgh, Edinburgh EH8 9XD, United Kingdom, Institut National de \\ la Santé et de la Recherche Médicale 2U106 and 3U288, Hôpital de la Pitié-Salpétrière, 75651 Paris Cedex 13, France, \\ and ${ }^{4}$ Départment of Neuropharmacology, Faculté de Pharmacie, 92960 Chatenay-Malabris, France
}

Mice lacking monoamine oxidase A (MAOA) display high levels of brain serotonin during the first postnatal week, causing an exuberant outgrowth of thalamocortical axons (TCAs) in layer IV of the somatosensory cortex (S1). We asked whether this exuberance is attributable to abnormal TrkB signaling, because modulation of TrkB signaling during a critical period dramatically influences the segregation and the morphology of TCAs in layer IV of the visual cortex. Using in situ hybridization and ELISA immunoassays, we showed that the levels of trkB mRNA and BDNF and neurotrophin-4 (NT-4) proteins are normal in the thalamus and the cortex of mice lacking MAOA during barrel field formation. Because the release of BDNF and NT-4 could be abnormal in MAOA knock-out (KO) mice, we tested whether abnormal TrkB signaling is required for TCA exuberance in MAOA-KO mice by generating mice lacking both trkB and
MAOA. Surprisingly, these mice exhibited more severe phenotypes than those found in MAOA-KO mice: a widespread tangential expansion of TCAs in layer IV of the cortex, resulting in a fusion of all sensory representations and a radial expansion of TCAs in layers II-III of the cortex. Careful examination of mice lacking trkB alone revealed subtle alterations of TCAs, with abnormal invasion of layer III. This study reveals the following: (1) expression of trkB, BDNF, and NT-4 are not modulated by an excess of serotonin during barrel formation, (2) TrkB signaling limits branching of TCAs in inappropriate supragranular cortical layers, and (3) serotonin and TrkB signaling act together to cluster thalamocortical axons in layer IV.

Key words: BDNF; NT-4; serotonin; somatosensory cortex; thalamocortical axons; TrkB signaling
Mice deficient for monoamine oxidase A [MAOA knock-out (KO) mice] display abnormally high levels of serotonin (5-HT) in the brain causing a lack of clustering of both thalamocortical axons (TCAs) and granular neurons in layer IV of the primary somatosensory cortex (S1) (Cases et al., 1996). The transient excess of brain 5-HT during postnatal days 0-7 (P0-P7) is entirely responsible for this phenotype (Cases et al., 1996; Vitalis et al., 1998). Morphologically, TCAs display abnormal tangential spreading (A. Rebsam, I. Seif, and P. Gaspar, unpublished results), and barrels appear fused along S1 (Cases et al., 1996). These findings could be explained as exuberant outgrowth caused by an excess of trophic factor.

One hypothesis concerning the mechanism by which TCAs pattern holds that developing competes for limiting amounts of target-derived trophic factors, such as neurotrophins. Consequently an excess of neurotrophins should eliminate competition among thalamic afferents. Indeed, infusion of brain-derived neurotrophic factor (BDNF) or neurotrophin 4 (NT-4) into the

Received Dec. 5, 2001; revised March 19, 2002; accepted March 20, 2002.

This work was supported by European Commission Grant BMH4 CT97-2412, the Wellcome Trust, the University of Edinburgh, Institut National de la Santé et de la Recherche Médicale, and Centre National de la Recherche Scientifique. We thank all members of the European Commission BIOMED Grant BMH4 CT97-2412 for sharing information. We thank Chantal Alvarez and Grace Grant for technical help, Linda Sharp for confocal assistance, Denis Lecren for photographic assistance, and Vince Ranaldi for animal care.

Correspondence should be addressed to Tania Vitalis at her present address: Department of Anatomy and Developmental Biology, University College London, London WC1E6BT, UK. E-mail: ucgatvi@ucl.ac.uk.

Copyright (C) 2002 Society for Neuroscience $0270-6474 / 02 / 224987-14 \$ 15.00 / 0$ visual cortex of kittens prevents the segregation of dorsal lateral geniculate nucleus axons into ocular dominance columns, possibly by increasing axonal arborization (Cabelli et al., 1995; Hata et al., 2000). These observations, however, do not show whether endogenous neurotrophins play a role in TCA segregation. To address this question, Cabelli et al. (1997) found that infusing TrkB-IgG (which sequesters TrkB ligands) into the visual cortex blocked the segregation of TCAs and decreased axonal arborization, suggesting that BDNF (or NT-4) acts principally to regulate the growth of TCAs within layer IV, similar to its effect in the developing retinotectal system in Xenopus (Cohen-Cory and Fraser, 1995; Cohen-Cory, 1999; Alsina et al., 2001).

In the rodent somatosensory system, trkB is transiently expressed in the somatosensory thalamus from P0 to P5 (Masana et al., 1993), whereas BDNF and TrkB are expressed in layer IV target cells from P5 to P10 (Itami et al., 2000). The P0-P10 period corresponds to the critical period of segregation of TCAs in layer IV of S1 and to the subsequent arrangement of granular neurons around these afferents (Rice and Van der Loos, 1977; Senft and Woolsey, 1991; Agmon et al., 1993, 1995). Thus, it is reasonable to think that TrkB signaling could promote axonal arborization in the somatosensory system, as in the visual system. So far, no obvious structural alterations of $\mathrm{S} 1$ have been observed in mice deficient for trkB, BDNF, NT-4/5, or BDNF and NT-4 (Henderson et al., 1995; Itami et al., 2000). No studies have explored the consequences of infusing exogenous BDNF into S1 during the critical period.

In this study, we investigated the hypothesis that the exuber- 
ance of TCAs displayed in MAOA-KO mice could be attributable to an abnormal modulation of the expression of the neurotrophin receptor TrkB and its known ligands BDNF and NT-4 in $\mathrm{S} 1$. We showed first that the level of expression of $\operatorname{trkB} \mathrm{mRNA}$ and BDNF and NT-4 proteins are unchanged in MAOA-KO mice. Because activity-dependent release of neurotrophins could be altered in MAOA-KO mice, we tested whether TrkB signaling is required for abnormal TCA development in MAOA-KO mice by generating mice lacking both $t r k B$ and MAOA. These mice display more severe alterations of the somatosensory cortex than those displayed by mice lacking MAOA or TrkB only. Sensory TCAs extend tangentially over a wider area than in MAOA-KO mice. More surprisingly, TCAs extend inappropriately into the supragranular layers II-III. Careful analysis of the somatosensory cortex of trkB-KO mice revealed subtle but significant alterations in the radial spread but not in the tangential segregation of TCAs. This study indicates a subtle role of TrkB signaling in limiting sensory thalamocortical outgrowth in inappropriate supragranular layers.

\section{MATERIALS AND METHODS}

\section{Mice}

trkB knock-out mice were generated with a targeted mutation in the catalytic domain (Klein et al., 1993) and were obtained on a mixed C57BL/6-Sv129 genetic background. MAOA knock-out mice displayed a deletion of exons 2 and 3 of the gene encoding MAOA (Cases et al., $1995)$ and were originally obtained and maintained on a $\mathrm{C} 3 \mathrm{H} / \mathrm{He}$ genetic background. Mice lacking trkB or MAOA will be referred to as trkB-KO or MAOA-KO mice. Mice lacking both trkB and MAOA [referred to as MAOA-trkB double knock-out (DKO) mice] were obtained in the F2 progeny from crosses between females heterozygous for MAOA and trkB and males hemizygous for MAOA and heterozygous for trkB. Genitors and pups were PCR genotyped for trkB and MAOA mutations. For trkB genotyping, the same primers as previously described by Klein et al. (1993) were used. For MAOA genotyping, two pairs of primers were used. The first pair was used to detect the presence of the transgene (5', CTCAGAAGTCGGATCTGAT in the H2-Kb; and 3', CAGTAGATTCACTACCAGTC in the interferon- $\beta$ gene). The other pair of primers corresponded to sequences only present in the normal allele $\left(5^{\prime}\right.$, GATTCTCTCCTATTGTCTCTG; and 3', AAAGACAGTTGTGAAGCCTCA). Animal procedures were conducted in strict compliance with approved institutional protocols and in accordance with the provisions for animal care and use described in the Scientific Procedures on Living Animals ACT 1986.

\section{Immunocytochemistry and histochemistry}

Tissue sample preparation. Postnatal mice were analyzed at P0 (day of birth), P2, P4, P5, P7, P9, P10, P11, P12, and P13. Pups were anesthetized and perfused transcardially with fresh fixative (4\% paraformaldehyde in $0.12 \mathrm{M}$ phosphate buffer, $\mathrm{pH}$ 7.4). After perfusion, brains were removed from the skull and weighed. In some cases, one hemisphere was separated from the rest of the brain by a section through the internal capsule and flattened between two glass slides separated by spacers. The rest of the brain was kept as one block. Blocks and flattened hemispheres were postfixed in fresh fixative and cryoprotected in $30 \%$ sucrose in phosphate buffer for $2-10 \mathrm{~d}$ before sectioning. Serial $46-\mu \mathrm{m}$-thick frozen sections were obtained in the coronal or tangential planes. Sections were used for immunocytochemistry, Nissl-staining, or cytochrome oxidase (CO) histochemistry as described below.

Immunocytochemistry. 5-HT immunocytochemistry (rat monoclonal antibody, 1:40; Harlan Sera-Lab, Loughborough, UK) was performed on frozen sections as described previously (Lebrand et al., 1996). Polyclonal antibodies raised against the serotonin transporter (SERT) (1:3000; Calbiochem-Merck, Darmstadt, Germany), and metabotropic glutamate receptor type 5 (mGluR5) (1:2000; Chemicon, Temecula, CA) were also used on free-floating sections. Briefly, sections were incubated overnight with the primary antibody diluted in PBS $+(0.1 \mathrm{~m}$ PBS with $0.2 \%$ gelatin and $0.25 \%$ Triton X-100). Then, sections were washed in PBS+ and incubated with secondary antibodies (biotinylated goat anti-rabbit and biotinylated goat anti-rat, 1:200; Dako, Glostrup, Denmark) for $2 \mathrm{hr}$ at room temperature. Sections were washed in PBS + and incubated with a streptavidin-biotin-peroxidase complex (1:200; Amersham Biosciences, Arlington Heights, IL) for $2 \mathrm{hr}$ at room temperature. Sections were then reacted with a solution containing $0.02 \%$ diaminobenzidine and $0.003 \%$ $\mathrm{H}_{2} \mathrm{O}_{2}$ in PBS, pH 7.6. All sections were mounted on 3-aminopropyltriethoxysilane-coated slides, air dried overnight, dehydrated, and coverslipped in DePeX.

Nissl staining. Complete series of tangential and coronal sections were Nissl stained as described previously (Rice and Van der Loos, 1977). Slides were immersed in a solution containing $0.05 \%$ thionine in acetate buffer, $\mathrm{pH} 5.5$, for 2-5 min. Then, sections were differentiated in $70 \%$ ethanol and dehydrated. Slides were coverslipped in DePeX.

Cytochrome oxidase histochemistry. Complete series of tangential and coronal sections were reacted for $\mathrm{CO}$ as described previously (WongRiley and Welt, 1980). In brief, sections were sequentially incubated 10 min in phosphate buffer $(0.1 \mathrm{M}), \mathrm{pH} 7.4$, with $10 \%$ sucrose, $0.2 \%$ cobalt chloride, and phosphate-buffered sucrose. Then, sections were incubated at $37^{\circ} \mathrm{C}$ in phosphate buffer containing $10 \%$ sucrose, $0.007 \%$ cytochrome $c, 0.002 \%$ catalase, and $0.05 \%$ diaminobenzidine until desired contrast was obtained (all products from Sigma, St. Louis, MO).

\section{DiI tracing of somatosensory thalamocortical axons}

Labeling of somatosensory thalamocortical axons with lipophilic carbocyanine dye $\left[1,1^{\prime}\right.$-dioctadecyl-3,3,3',3'-tetramethylindocarbocyanine (DiI); Molecular Probes, Eugene, OR] was performed in fixed tissues (wild type, $n=4$; MAOA-trkB-DKO, $n=3$ ) at P8. Perfused brains were sectioned in the coronal plane at the level of the ventrobasal thalamus (VB). DiI crystals were dissolved in dimethylformamide (DMF) (10\% solution; Sigma). The solution was mixed in a warm solution of $3 \%$ agarose. This allows the excess of DMF to evaporate and to form DiI microdrops at the surface of agarose. DiI microdrops were picked up on a broken tip of a glass micropipette and carefully inserted into the VB. Injected brains were stored at room temperature in the dark for 1-2 months. Then, injected brains were sectioned in the coronal plane on a vibratome. Sections $(200 \mu \mathrm{m})$ were collected in PBS and analyzed by confocal microscopy (Leica, Nussloch, Germany).

\section{In situ hybridization for trkB}

trkB cRNA probe, corresponding to the tyrosine kinase domain of the protein, was used (Klein et al., 1993). The plasmid was linearized with BamHI for antisense RNA synthesis by T7 polymerase and with EcoRI for sense RNA synthesis by T3 polymerase. The in vitro transcription was performed using the Promega (Madison, WI) kit, and probes were labeled with [ $\left.{ }^{35} \mathrm{~S}\right] \mathrm{UTP}(>1000 \mathrm{Ci} / \mathrm{mmol}$; Amersham Biosciences). In situ hybridization for cRNA probes was performed on fresh frozen brain sections $(15-\mu \mathrm{m}$-thick). Tissue sections were postfixed for $15 \mathrm{~min}$ in $4 \%$ paraformaldehyde, washed in PBS, acetylated, washed in PBS, dehydrated, and air dried. Sections were covered with hybridization buffer containing $5 \times 10^{4} \mathrm{cpm} / \mu \mathrm{l}$ of the ${ }^{35} \mathrm{~S}$-trkB probes and then incubated overnight in a humid chamber at $50^{\circ} \mathrm{C}$. Washes were performed as described previously (Fontaine and Changeux, 1989). Autoradiograms were obtained by apposing the sections to hyperfilms ( $\beta$-max; Amersham Biosciences) for several days. Autoradiographic films were developed in D19 (Eastman Kodak, Rochester, NY) for 3 min at $20^{\circ} \mathrm{C}$ and fixed in A14 (Ilford, Paranus, NJ) for 5 min. For histological analyses, the slides were dipped in photographic emulsion (NTB2; Eastman Kodak) and exposed for $\sim 10 \mathrm{~d}$. After development of the emulsion, the sections were counterstained with Nissl.

\section{HPLC analysis}

$\mathrm{P} 0$ and P7 pups were decapitated, and the brains were rapidly removed and dissected. One cortical hemisphere was dissected out from the remainder of the brain, and both pieces were rapidly frozen on dry ice. Samples were kept at $-80^{\circ} \mathrm{C}$ before being subjected to HPLC. Samples were first sonicated for $5 \mathrm{sec}$ in $10 \mathrm{vol}(\mathrm{v} / \mathrm{w})$ of $0.1 \mathrm{~N}$ perchloric acid and $0.05 \%$ sodium metabisulfite. Supernatant $(200 \mu \mathrm{l})$ was collected after centrifugation $(20 \mathrm{~min}, 30,000 \times g)$. Supernatant aliquots were neutralized on ice for $10 \mathrm{~min}$ by adding $20 \mu \mathrm{l}$ of $2 \mathrm{M}$ potassium phosphate buffer, $\mathrm{pH} 7.4$; endogenous ascorbic acid was degraded by adding $10 \mu \mathrm{l}$ of $0.02 \%$ ascorbate oxidase $(5 \mathrm{~min})$. After centrifugation for $20 \mathrm{~min}$ at $30,000 \times \mathrm{g}$, $10 \mu \mathrm{l}$ of the supernatant was collected and injected onto a Beckman Ultrasphere 5- $\mu \mathrm{m}$ IP column (Beckman Coulter, Fullerton, CA). The

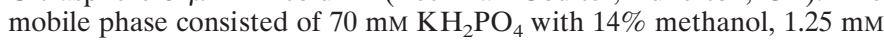
octane sulfonate, $0.1 \mathrm{~mm}$ sodium EDTA, and $2.1 \mathrm{~mm}$ triethylamine, with the $\mathrm{pH}$ adjusted to 3.02 with solid citric acid. Serotonin and dopamine 
and their respective metabolites, 5-hydroxyindolacetic acid and dihydroxyphenylacetic acid, eluted from the column were quantified by electrochemical detection (at $0.65 \mathrm{~V})$, and concentrations were calculated in picomoles per milligram of brain (Hamon et al., 1988).

\section{ELISA immunoassay}

Preparation of samples for BDNF and NT-4 protein measurement. Brains of wild-type and MAOA-KO mice aged P3, P4, P7, P10, and P90 were rapidly removed from their skulls. S1 cortices were rapidly dissected out, weighed, and snap frozen on dry ice. Samples were stored at $-80^{\circ} \mathrm{C}$ before homogenization. BDNF and NT-4 were extracted from brain tissue by homogenization ( $1 \mathrm{w} / 10 \mathrm{v}$ dilution) in $100 \mathrm{~mm}$ piperizine ethane sulfonic acid homogenization buffer, $\mathrm{pH} 7.0$, containing $500 \mathrm{~mm} \mathrm{NaCl}$, $0.2 \%$ BSA, $0.2 \%$ Triton $\mathrm{X}-100,0.1 \% \mathrm{NaN}_{3}$, and fresh protease inhibitors $(2 \mu \mathrm{g} / \mathrm{mg}$ aprotinin, $2 \mathrm{~mm}$ EDTA, $10 \mu \mathrm{M}$ leupeptin, $1 \mu \mathrm{M}$ pepstatin, and $200 \mu \mathrm{M}$ PMSF) using ground-glass Dounces (Pollock et al., 2001). Homogenates were centrifuged at $16,000 \times g$ for $20 \mathrm{~min}$ to pellet and stored at $-80^{\circ} \mathrm{C}$ before BDNF and NT-4 ELISAs. BDNF and NT-4 protein levels were measured with standard two-antibody sandwich ELISA (BDNF or NT-4 $\mathrm{E}_{\max }$ immunoassay system; Promega). BDNF and NT-4 ELISAs were performed according to the protocol of the manufacturer. The value for an individual S1 cortex represents the mean of three independent measures. Final values represent the mean of individual values obtained at P3-P4 (wild type, $n=6$; MAOA-KO, $n=8$ ), P7 (wild type, $n=4$; MAOA-KO, $n=4$ ), P10 (wild type, $n=2$; MAOA-KO, $n=$ 3 ), and P90 (wild type, $n=3$, MAOA-KO, $n=4$ ). Final values obtained at P3-P4, P7, and P90 were compared using an unpaired Student's $t$ test.

\section{Morphometric analysis}

Counts of pyknotic profiles. Coronal sections of P5, P7, and P9 pups, stained for Nissl, were analyzed using a $40 \times$ objective and a millimetric eyepiece. The number of pyknotic profiles was counted in layers II-III, layer IV, and layer V of the somatosensory cortex (S1) and in the ventrobasal thalamic nuclei. In S1, pyknotic profiles were counted at bregma level -1.94 posterior and -3.1 lateral. Three sections were counted for each case, and the values from four animals were obtained for each mouse strain. Values derived from wild-type, MAOA-KO, trkB-KO, and MAOA-trkB-DKO mice were compared using an unpaired Student's $t$ test.

Cortical analysis. The barrel field area was measured from tangentially sectioned hemispheres of P7 cortices, as described previously (Vitalis et al., 1998). Reconstructions of the barrel field were obtained from complete series of CO-reacted sections ( $n=4$ for wild-type, MAOA-KO, trkB-KO, and MAOA-trkB-DKO mice) and 5-HT-reacted sections $(n=$ 4 for wild-type, MAOA-KO, trkB-KO, and MAOA-trkB-DKO mice). The neocortex was distinguished from surrounding territories by a difference in $\mathrm{CO}$ activity at its borders or by the presence of a dense network of serotoninergic terminals and was outlined. From these reconstructions, the entire neocortical area, the area of intense CO activity (S1 plus S2), and the area of "5-HT hyperinnervation" were measured. Values derived from each strain were compared using an unpaired Student's $t$ test.

Using a Leica digital camera and TCNST software (Leica), the length and width of individual barrels (B2, C2, D2, B3, C3, and D3) were measured from tangentially sectioned hemispheres reacted for $\mathrm{CO}(n=$ 4 for wild-type and trkB-KO mice). Values derived from each strain were compared using an unpaired Student's $t$ test.

The thickness of layers II-IV and layers II-VI were measured in Nissl-stained coronal sections, using an eyepiece graticule $(10$ and $20 \times$ objectives). Measures were taken along a line perpendicular to the pial surface, at two different stereotaxic levels: one in the posteromedial barrel subfield (PMBSF) (level, -1.94 posterior and -3.1 lateral to bregma) and the other in the anterior snout (AS) (level, -0.82 anterior and -3.1 lateral to bregma). Measures were obtained from $\mathrm{P} 9$ pups (wild type, $n=4$; MAOA-KO, $n=4$; $\operatorname{trkB}-\mathrm{KO}, n=4$; MAOA-trkB-DKO, $n=$ $6)$. Values derived from each strain were compared using an unpaired Student's $t$ test.

The thickness of the SERT-immunoreactive plexuses was measured from coronal sections of P7 pups using an eyepiece graticule $(20 \times$ objective). Measures were taken along a line perpendicular to the pial surface, at bregma level -1.94 posterior and -3.1 lateral. Four measures were taken for each case ( $n=4$ for wild-type and MAOA-KO pups; $n=$ 5 for trkB-KO and MAOA-trkB-DKO pups). Values derived from each strain were compared using an unpaired Student's $t$ test.

\section{RESULTS}

\section{Does excess 5-HT modulate trkB, BDNF, and NT-4 in the barrel field?}

We tested whether abnormally high levels of 5-HT modulate the expression of trkB mRNA and the levels of BDNF and NT-4 proteins in MAOA-KO mice.

\section{Expression of trkB $m R N A$ in MAOA-KO mice during the critical period of barrel field formation}

We performed in situ hybridization with riboprobes corresponding to the tyrosine kinase domain of $\operatorname{trk} B$ during barrel field formation from P0 to P15. In agreement with previous observations (Masana et al., 1993; Singh et al., 1997; Itami et al., 2000), we found that $t r k B$ is present in the somatosensory thalamic neurons from P0 to P15 and layer IV cortical neurons from P5 to P10 during critical periods of barrel field formation (data not shown). We also found that increased brain levels of 5-HT, in MAOA-KO mice, has no visible effect on trkB mRNA expression (data not shown).

\section{Levels of BDNF and NT-4 protein in MAOA-KO mice during the critical period of barrel field formation}

To determine whether MAOA deficiency modified the levels of BDNF and NT-4 proteins, we measured the levels of BDNF and NT-4 in the barrel cortex of wild-type and MAOA-KO mice using ELISA immunoassays. In the wild-type barrel cortex, the levels of BDNF and NT-4 proteins were highest between P3 and $\mathrm{P} 7$ and decreased rapidly to adult values by $\mathrm{P} 10$ (Fig. $1 A, B)$. This result is in agreement with previous studies showing that levels of BDNF and NT-4 proteins peak between P7 and P14 in the rat neocortex (Das et al., 2001). In MAOA-KO mice, the levels of BDNF and NT-4 proteins were normal during the period of barrel field development from $\mathrm{P} 3$ to $\mathrm{P} 7$ (Fig. 1 $A, B$ ). However, the level of BDNF protein did not decrease by P10 and in adults (Fig. $1 B$ ), suggesting that abnormal levels of 5-HT such as those displayed in MAOA-KO mice could not modify the levels of BDNF after P7. In agreement with this finding, high levels of 5-HT have been shown previously to influence the levels of BDNF synthesis in specific areas of the adult rat brain (Zetterstrom et al., 1999).

Together, these results show that $\operatorname{trk} B$ mRNA expression and BDNF and NT-4 protein levels are normal in MAOA-KO mice during the period of barrel field development. Because activitydependent release of BDNF or NT-4 could be altered in MAOA-KO mice, we generated MAOA-trkB-DKO mice.

\section{General development of trkB-KO and MAOA-trkB-DKO mice}

MAOA-trkB-DKO and trkB-KO mice and their various controls were obtained in the $\mathrm{F} 2$ progeny from crosses between females heterozygous for both MAOA and trkB and males hemizygous for MAOA and heterozygous for trkB. The size of the litter and the weight of the pups of the different genotypes were evaluated before perfusion. At P0, the size of the litter was similar to controls $(10 \pm 1.3$ pups; mean \pm SEM $)$ with a normal sex ratio. MAOA-trkB-DKO and trkB-KO mice were obtained at the expected frequency.

trkB-KO mice are hypomorphic, and most pups (80\% estimated) die during the first postnatal week as a result of feeding and breathing problems probably attributable to the increased cell death observed in the CNS (facial motor nucleus) and peripheral (trigeminal) nervous system (Klein et al., 1993). Despite 

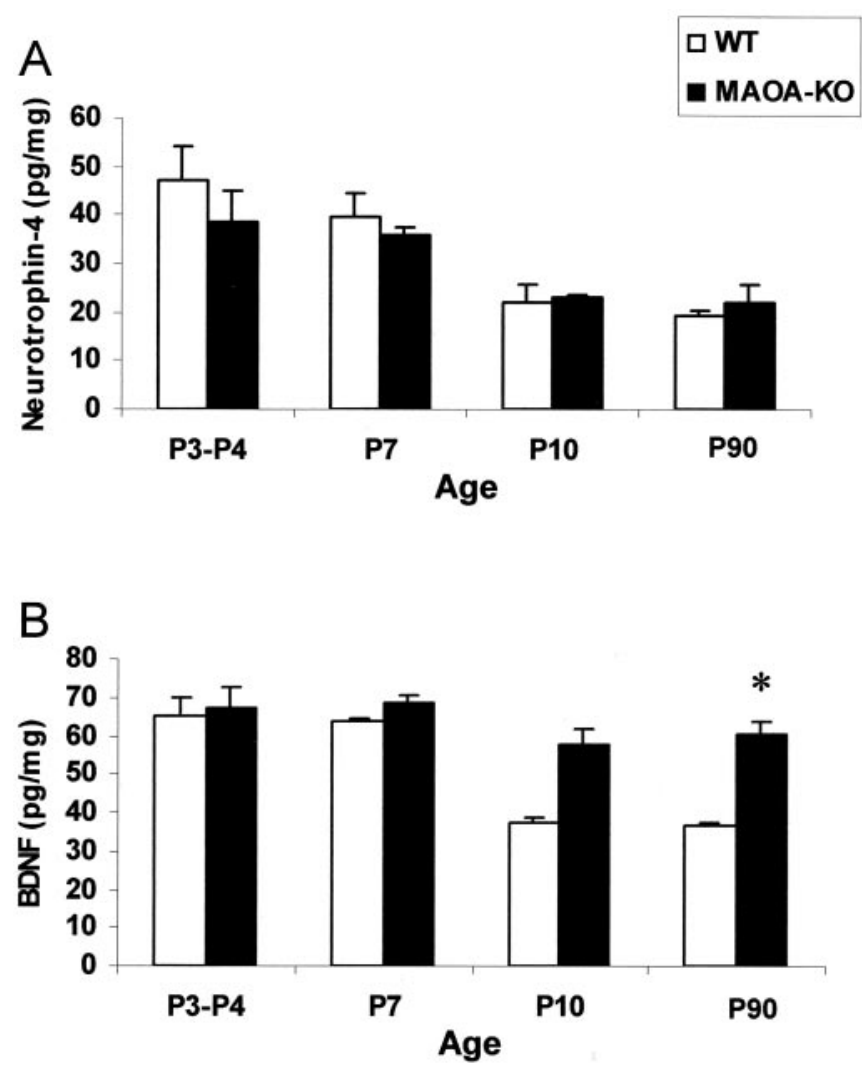

Figure 1. Levels of BDNF $(A)$ and NT-4 $(B)$ proteins in S1 of wild-type $(W T)$ and MAOA knock-out mice using ELISA immunoassays. All values are expressed in picograms per milligram of protein. All values represent the means $\pm \mathrm{SD}$ (wild type: $\mathrm{P} 3-\mathrm{P} 4, n=6 ; \mathrm{P} 7, n=4 ; \mathrm{P} 10, n=$ 2; P90, $n=3$; MAOA-KO: P3-P4, $n=8$; $\mathrm{P} 7, n=4$; $\mathrm{P} 10, n=3$; $90, n=$ 4). $* p<0.05$ indicates that the results are statistically significant between the groups analyzed (Student's $t$ test).

a similar reduction in body and brain weights (Fig. $2 A, B$ ) and in sizes of the facial motor $(23-25 \%)$ and the trigeminal nuclei (20-22\%), MAOA-trkB-DKO mice survived longer than trkB-KO mice, with numerous pups dying after P7 ( 40\%).

In all animals, cortical lamination appeared normal on coronal sections at the level of the PMBSF and the AS. However, the thickness of layers II-IV and layers II-V I displayed a significant reduction at $\mathrm{P} 9$ in both trkB-KO and MAOA-trkB-DKO mice (Table 1). The decrease in the cortical thickness affected mostly layers II-IV and was slightly more severe in the anterior part of the cortex corresponding to AS. At this level, the thickness of layers II-IV displayed a $24 \%$ reduction in trkB-KO mice and a $18 \%$ reduction in MAOA-trkB-DKO mice compared with wildtype mice.

\section{Analysis of cell death in S1 and VB}

In view of the well established survival-promoting effects of BDNF and NT-4, we investigated whether any increased cell death was occurring in trkB-KO and MAOA-trkB-DKO mice during the critical period of TCA refinement in S1. We counted the density of pyknotic profiles (Nissl-stained shrunken nuclei) in layers II-III, IV, and V of S1 at P5 and P9 in our different strains (Fig. 2C,D). MAOA-KO mice showed a slight reduction in the density of pyknotic profiles in layers II-III and V at P5 but not at P9 compared with wild-type mice. In trkB-KO mice, there was a slight but significant increase in the number of pyknotic profiles compared with wild-type mice in layer V by P5 and in layers II-III, IV, and V by P9. The increase in cell death was mostly restricted to the rostral portion of S1 corresponding to AS. Interestingly, MAOA-trkB-DKO mice showed similar densities of pyknotic profiles to those observed in wild-type or MAOA-KO mice. Importantly, we observed no changes in the density of pyknotic profiles in layer IV at P5, during the critical period of barrel field formation.

Similar to what was observed in the cortex, we found a slight reduction in the number of pyknotic profiles in the $\mathrm{VB}$ of MAOA-KO mice compared with wild-type mice at P5 but not P9 (Fig. 2C,D). In trkB-KO mice, cell death was increased at P9 in the VB (Fig. $2 C, D$ ). MAOA-trkB-DKO mice had comparable levels of cell death with those displayed by wild-type or MAOA-KO mice (Fig. 2C,D).

Together, these results suggest that increased 5-HT could delay or prevent the cell death induced by trkB deficiency in S1 and VB.

\section{5-HT and 5-hydroxyindoleacetic acid brain levels}

We looked for general differences in total brain 5-HT and 5-hydroxyindoleacetic acid (5-HIAA) levels at P0 and P7 in the different strains (Fig. 2E,F). We found similar levels of 5-HT in the brains of wild-type and trkB-KO pups at P0 and P7. A slight but statistically significant increase in 5-HIAA levels was observed at $\mathrm{P} 0$ and $\mathrm{P} 7$ in trkB-KO mice, suggesting that 5-HT metabolism could be slightly enhanced in trkB-KO mice. MAOA-KO mice had a $900 \%$ increase in 5-HT levels at P0 and a $400 \%$ increase at P7 compared with wild-type mice. Similar 5-HT levels were found in MAOA-KO and MAOA-trkB-DKO mice at P0, although, at P7, MAOA-trkB-DKO mice had higher levels of 5-HT. A dramatic decrease in 5-HIAA levels was similarly observed in MAOA-KO and MAOA-trkB-DKO mice. In contrast, we found no statistically significant increase in dopamine and 3,4-dihydroxyphenylacetic acid levels in trkB-KO and MAOAtrkB-DKO pups compared with wild-type and MAOA-KO pups, respectively (data not shown).

\section{Deficiency of trkB in MAOA-KO mice increased the alterations of the barrel field observed in MAOA-KO mice}

\section{Cytochrome oxidase histochemistry}

$\mathrm{CO}$ histochemistry allows the visualization of regions with heightened metabolic activity and is classically used to examine barrel field organization. At this level, $\mathrm{CO}$ activity is localized in both dendrites of cortical neurons and TCA terminals (WongRiley et al., 1980). In trkB-KO mice, the intensity of CO activity was similar to that of wild-type mice, and barrels were normally organized in the entire barrel field in the representations corresponding to the main whiskers (PMBSF), tactile hairs located on the anterior snout (AS), the lower lip (LL), the hindpaw (HP), and the forepaw (FP) (Fig. 3A,B). However, there was a $27-32 \%$ reduction in the area of the barrel field representation. This decreased area was proportional to the reduction of the size of the flattened hemisphere (27-31\% reduction of PMBSF area), suggesting that the reduction of the barrel field area was attributable to the hypotrophy of the brain. Individual barrels displayed a similar reduction proportional to the reduction of the barrel field (reduction of barrel lengths: B2, 29-33\%; C2, 25-29\%; D2, $27-32 \%$; B3, 28-34\%; C3, 28-34\%; D3, 28-34\%; reduction of barrel widths: B2, 25-30\%; C2, 24-31\%; D2, 25-29\%; B3, 28$32 \%$; C3, 28-33\%; D3, 28-34\%) (data not shown). In MAOA-KO mice, the somatosensory map was profoundly modified as reported 

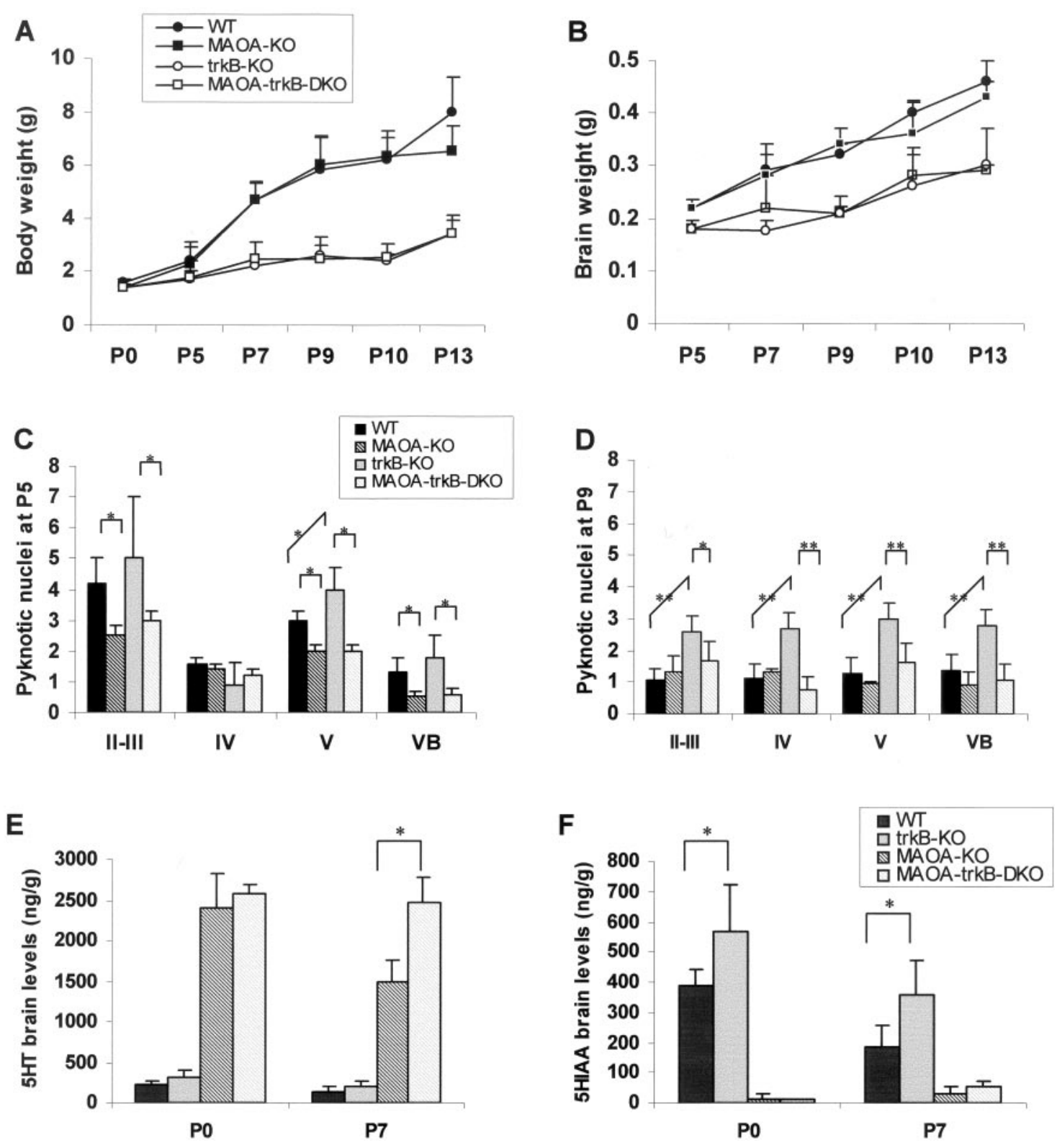

Figure 2. Comparison of the general development of wild-type $(W T)$, MAOA-KO, trkB-KO, and MAOA-trkB-DKO mice. $A, B$, Body $(A)$ and brain $(B)$ growth curves in wild-type, MAOA-KO, trkB-KO, and MAOA-trkB-DKO mice during postnatal development. Values are expressed in grams and represent the mean $\pm \mathrm{SD}$. Note the similarity between trkB-KO and MAOA-trkB-DKO mice in both body and brain growth. $C, D, C$ ell death in $\mathrm{S} 1$ and the VB of wild-type, trkB-KO, MAOA-KO, and MAOA-trkB-DKO mice at P5 and P9. $C, D$, The number of pyknotic nuclei (Nissl-stained shrunken nuclei per $100,000 \mu \mathrm{m}^{2}$ of tissue) was counted in layers II-III, IV, and V of S1 and in VB. Values are mean \pm SEM of four animals. ${ }^{*} p<0.05$ and ${ }^{* *} p<$ 0.001 indicate that the results are statistically different between the groups analyzed (Student's $t$ test). $C$, At P5, the number of pyknotic nuclei is slightly increased in layer $\mathrm{V}$ of trkB-KO mice. Interestingly, MAOA-trkB-DKO mice do not display this increase. $D$, At P9, the number of pyknotic nuclei is increased in layers II-III, IV, and V and in VB of trkB-KO mice. As at P5, MAOA-trkB-DKO mice do not display this increase in cell death. $E$, $F$, Whole-brain amounts of 5-HT and 5-HIAA in the brains of $\mathrm{P} 0$ and P7 wild-type, trkB-KO, MAOA-KO, and MAOA-trkB-DKO mice. E, At P0 and P7, 5-HT levels are similar in wild-type and trkB-KO mice. At P0, MAOA-trkB-DKO mice have similar 5-HT levels to those displayed by MAOA-KO mice. However, at P7, 5-HT levels are significantly higher in MAOA-trkB-DKO mice than in MAOA-KO mice $(41 \%$ increase; $* p<0.005$; Student's $t$ test). F, 5-HIAA levels are significantly increased in P0 and P7 trkB-KO mice compared with wild-type mice $(31$ and $47 \%$ increase, respectively; $* p<$ 0.05; Student's $t$ test). 5-HIAA levels are drastically reduced at P0 and P7 in MAOA-KO and MAOA-trkB-DKO mice. Values are expressed in nanograms per gram of wet brain and represent the mean $\pm \mathrm{SD}$ (P0: wild type, $n=4$; trkB-KO, $n=4$; MAOA-KO, $n=4$; MAOA-trkB-DKO, $n=$ 3; P7: wild type, $n=6$; trkB-KO, $n=5$; MAOA-KO, $n=7$; MAOA-trkB-DKO, $n=3$ ).

previously (Cases et al., 1996) (Fig. 3A,C). Most of the PMBSF and AS representations were fused, and separations were only maintained between the representations of AS and LL, LL and FP, and FP and HP. In the mixed genetic background used in this study, there was a variation in the intensity of the phenotype. In most cases (6 of 10), some barrels located in the PMBSF remained, and blobs of $\mathrm{CO}$ activity corresponding to the fusion of several barrels were observed in all cases analyzed in PMBSF and in the caudal portion of AS (Fig. 3C). This genetic variation of the consequence of MAOA inactivation has been reported previously (Vitalis et al., 1998; Salichon et al., 2001). In MAOA-trkB-DKO mice, the intensity of $\mathrm{CO}$ activity was greatly reduced in the cortex 
Table 1. Cortical thickness in wild-type, MAOA-KO, trkB-KO, and MAOA-trkB-DKO pups at age P9

\begin{tabular}{|c|c|c|c|c|}
\hline \multirow[b]{3}{*}{ Genotype } & \multicolumn{4}{|c|}{ Thickness of cortical layers $(\mu \mathrm{m})$} \\
\hline & \multicolumn{2}{|l|}{ II-IV } & \multicolumn{2}{|l|}{ II-VI } \\
\hline & -0.82 & -1.94 & -0.82 & -1.94 \\
\hline Wild type $(n=4)$ & $403 \pm 16$ & $386 \pm 17$ & $1122 \pm 30$ & $1071 \pm 50$ \\
\hline MAOA-KO $(n=4)$ & $395 \pm 20$ & $360 \pm 25$ & $1100 \pm 40$ & $1091 \pm 30$ \\
\hline $\operatorname{trkB}-\mathrm{KO}(n=4)$ & $305 \pm 7^{* *, \infty}$ & $305 \pm 21^{*, \circ}$ & $937 \pm 15^{* *, \circ \circ}$ & $935 \pm 50^{* *, \circ \circ}$ \\
\hline MAOA-trkB-DKO $(n=6)$ & $328 \pm 15^{*}$ & $303 \pm 20^{*, \circ}$ & $1024 \pm 27^{* \bullet} \bullet$ & $943 \pm 36^{*}$ \\
\hline
\end{tabular}

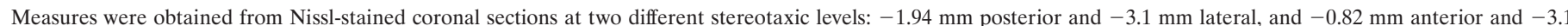
$\mathrm{mm}$ lateral to bregma. Values are means \pm SEMs.

*Statistical difference relative to the wild-type group ( $p<0.05$; Student's $t$ test).

**Statistical difference relative to the wild-type group ( $p<0.01$; Student's $t$ test).

${ }^{\circ}$ Statistical difference relative to the MAOA-KO group ( $p<0.05$; Student's $t$ test).

${ }^{\circ}$ Statistical difference relative to the MAOA-KO group ( $p<0.01$; Student's $t$ test).

-Statistical difference relative to the trkB-KO group ( $p<0.01$; Student's $t$ test).
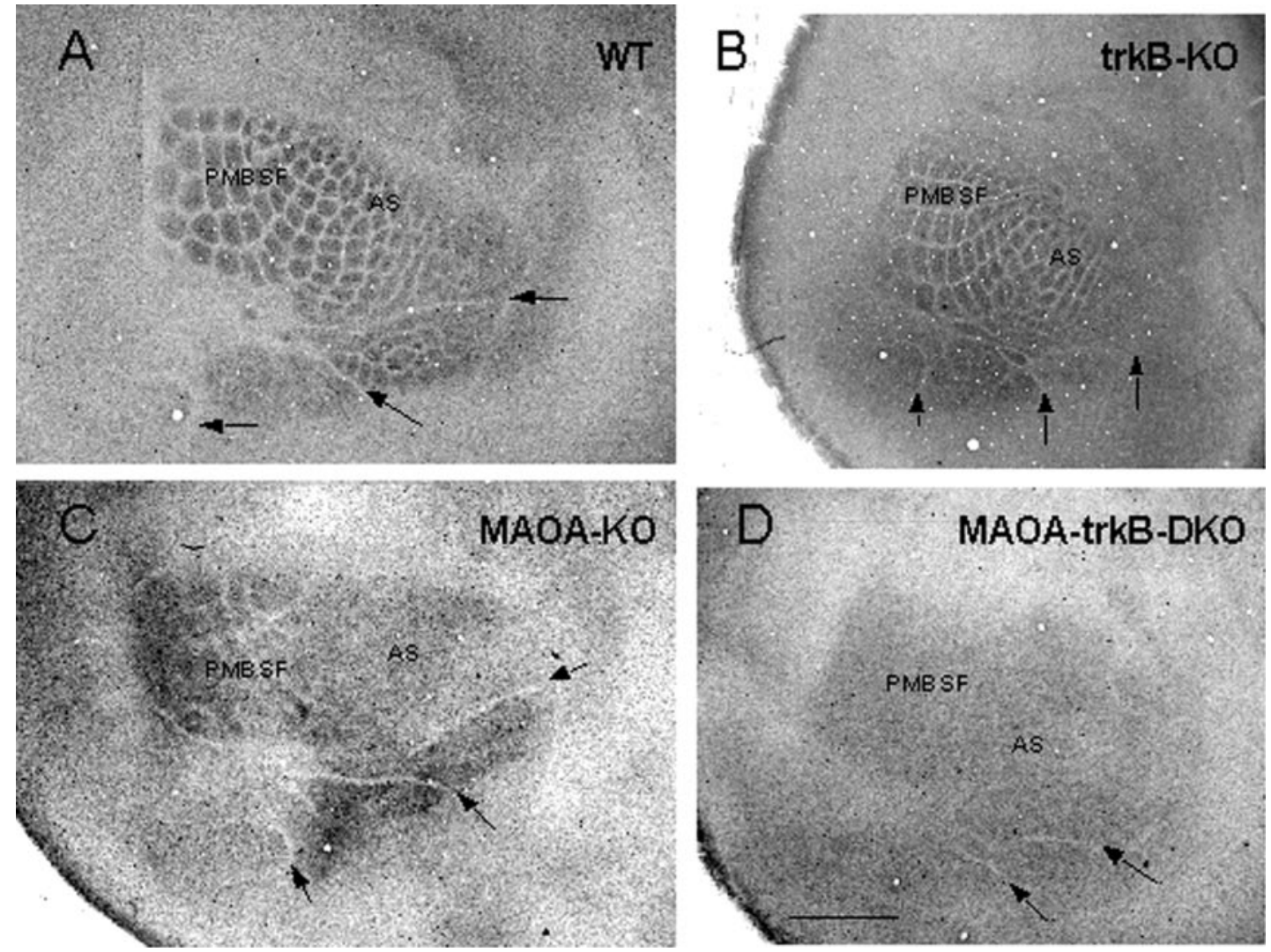

Figure 3. Flattened sections of P9 wild-type $(W T)(A)$, trkB-KO $(B)$, MAOA-KO $(C)$, and MAOA-trkB-DKO $(D)$ pups reacted for cytochrome oxidase activity. Reconstruction of $\mathrm{S} 1$ has been made in $A . A, B$, Note the blobs of cytochrome oxidase activity in the PMBSF and the AS representation in wild-type $(A)$ and trkB-KO $(B)$ mice. $C$, Section showing a complete blurring of the AS representation and a remaining barrel-like organization in PMBSF of an MAOA-KO pup. $D$, Section showing a complete lack of barrel and barrel-like $C O$ active blobs in PMBSF and AS representation of an MAOA-trkB-DKO pup. Note the decrease of CO activity displayed in the MAOA-trkB-DKO pup. Arrows indicate large septae that separate AS and LL, LL and FP, and FP and HP. Scale bar, $1 \mathrm{~mm}$.

compared with wild-type, trkB-KO, or MAOA-KO mice. On flattened sections, the edges of the barrel field representation were difficult to identify precisely in one-half of the cases analyzed (four of eight). However, separations between AS and LL, LL and FP, and $\mathrm{FP}$ and $\mathrm{HP}$ were visible in the cases, presenting a sufficient $\mathrm{CO}$ activity (Fig. 3D).

To gain more insight into the alterations of the barrel field in MAOA-trkB-DKO and trkB-KO mice, we next used specific markers of thalamocortical axons and cortical neurons.

\section{Organization of thalamocortical axons in trkB and $M A O A$-trkB-DKO mice}

Thalamic neurons do not synthesize 5-HT but accumulate 5-HT through the SERT located on thalamocortical axons and terminals from embryonic day 15 to P10 (Lebrand et al., 1996, 1998). We took advantage of this transient expression to specifically visualize TCAs with 5-HT or SERT immunoreactivity (IR) in trkB-KO and MAOA-trkB-DKO mice. 

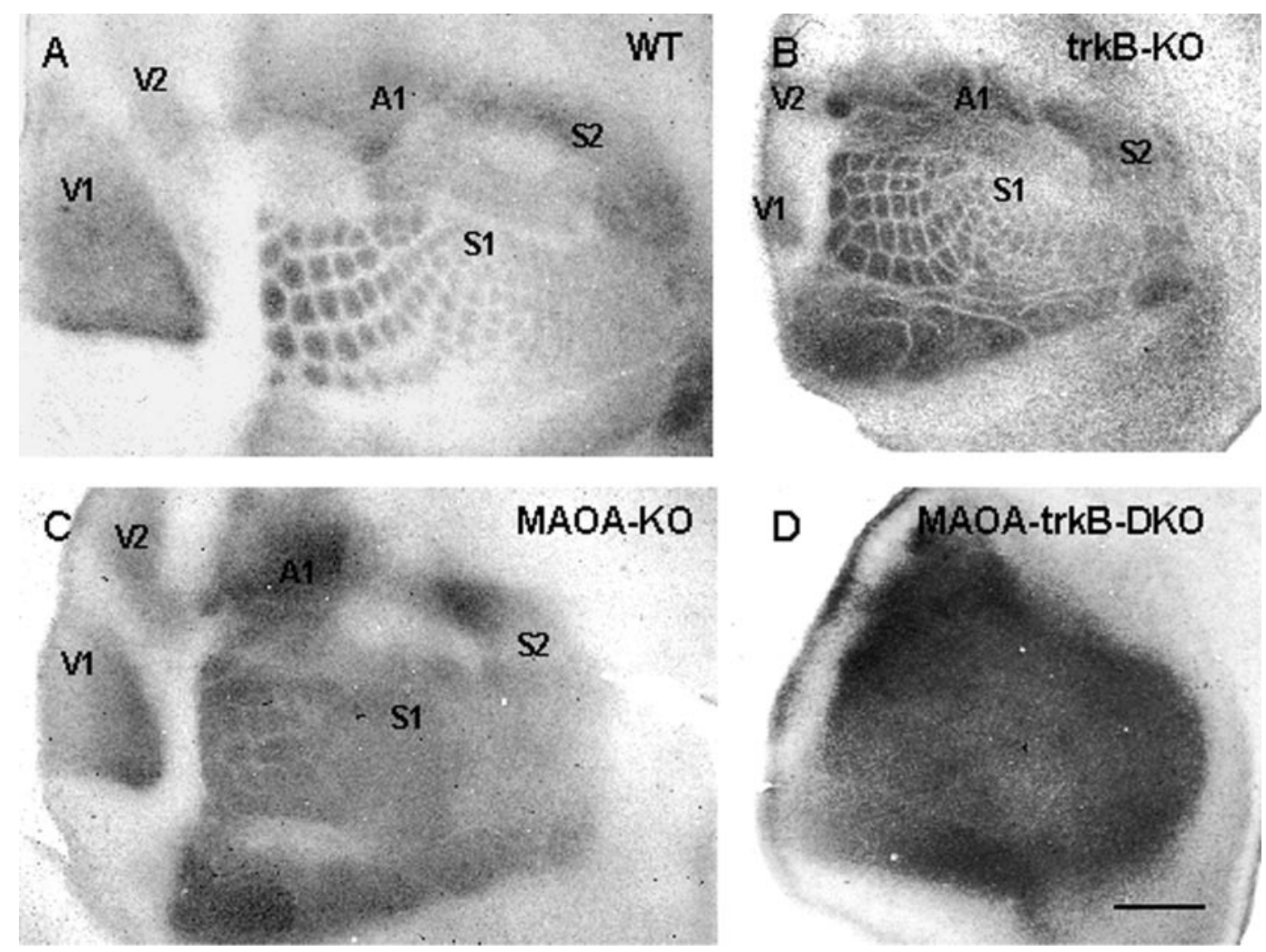

Figure 4. Flattened sections of P7 wild-type $(W T)(A)$, trkB-KO $(B)$, MAOA-KO $(C)$, and MAOA-trkB-DKO $(D)$ pups immunoreacted to 5-HT. $A-C$, In wild-type $(A)$, trkB-KO $(B)$, and MAOA-KO $(C)$ pups, 5-HT-IR is strong in $\mathrm{S} 1$, V1, and A1 cortices and in the $\mathrm{S} 2$ and $\mathrm{V} 2$ cortices. $A, B$, In wild-type $(A)$ and trkB-KO $(B)$ pups, barrels are clearly defined in S1. $C$, In MAOA-KO pups, a barrel-like organization remains in the caudalmost portion of S1. $D$, The fusion of all barrels in S1 is observed in MAOA-trkB-DKO pups. Strikingly, a fusion is also observed between the primary and secondary areas. In particular, S1 is fused with A1, S2, and V2. Note a similar reduction in the size of the flattened hemisphere in trkB-KO and MAOA-trkB-DKO pups. Scale bar, $1 \mathrm{~mm}$.

Tangential organization of thalamocortical axons in trkB-KO and $M A O A$-trkB-DKO mice. At $\mathrm{P} 7$, flattened sections of wild-type cortex immunoreacted for 5-HT showed a dense network of immunolabeled terminals in the primary somatosensory cortex (S1), the secondary somatosensory area (S2), the primary auditory (A1), and the primary and the secondary visual (V1 and V2) cortices. In S1, barrels were clearly delineated in PMBSF, AS, FP, $\mathrm{HP}$, and LL representations. Sections of trkB-KO mice showed clear individual barrels in PMBSF and AS (Fig. 4, compare $A, B$ ). In MAOA-KO mice, strong 5-HT immunolabeling delineated the three primary and the two secondary sensory cortices (Fig. 4C). In $\mathrm{S} 1$, the barrel field representation was fused, although, in $70 \%$ of the cases, few barrels and blobs of immunolabeling remained (Fig. 4C), similar to what was observed with $\mathrm{CO}$ activity. In MAOA-trkB-DKO mice, the barrel field representation was more severely altered than in MAOA-KO mice (Fig. 4, compared $C, D)$. 5-HT immunostaining revealed the fusion of all of the presumptive primary cortices (Fig. $4 D$ ). Whereas the fusion of S1, A1, and S2 was always observed, limits between the visual and the somatosensory or the visual and the auditory cortices remained defined in some cases (four of nine) (data not shown). The fusion of 5-HT-immunostained areas appeared also on coronal sections (see Fig. 6). On flattened sections, the area displaying 5-HT immunoreactivity as a proportion of the entire neocortical area was dramatically increased (43-44\%) in MAOA-trkB-DKO mice compared with MAOA-KO or wild-type mice. The discrepancy between the extension of cortical areas observed using 5-HT immunostaining (see above) and using $\mathrm{CO}$ histochemistry could suggest that $\mathrm{CO}$ histochemistry reveals the $\mathrm{CO}$ activity displayed by layer IV neurons rather than thalamocortical axons in MAOAtrkB-DKO mice.

Radial organization of thalamocortical axons in trkB-KO mice. Developing TCAs were organized similarly in wild-type and trkB-KO mice at P0 and P2 (data not shown). By P4, a few barrels corresponding to the main whiskers were segregated in layer IV of wild-type mice (Fig. $5 A, B$ ), with axons extending to the pial surface. In contrast, in trkB-KO mice, TCAs showed no segregation at $\mathrm{P} 4$ (Fig. 5C,D). By $\mathrm{P} 7$ in wild-type mice, barrels were segregated in the entirety of $\mathrm{S} 1$ (as judged on tangential sections). In coronal sections, axons rarely extended into the upper part of layers II-III and were never seen in contact with the pial surface (Senft and Woolsey, 1991; Agmon et al., 1993, 1995) (Fig. 5). In trkB-KO mice, barrels were normally segregated in the entirety of S1 by P7. However, their morphology appeared less refined, numerous TCAs terminated into the upper part of layers II-III, and a few TCAs maintained contacts with the pial surface (Fig. 5 ). The radial length of SERT-IR plexus was $19-21 \%$ greater in trkB-KO mice than in wild-type mice. Together, these results show that trkB-KO mice display subtle alterations of thalamocortical projections.

Radial organization of thalamocortical axons in $M A O A$-trkBDKO mice. In MAOA-KO and MAOA-trkB-DKO mice, TCAs were normally restricted to the lower tier of the developing cortical plate at P2 (Fig. 6A,B). Tangentially, 5-HT- and 

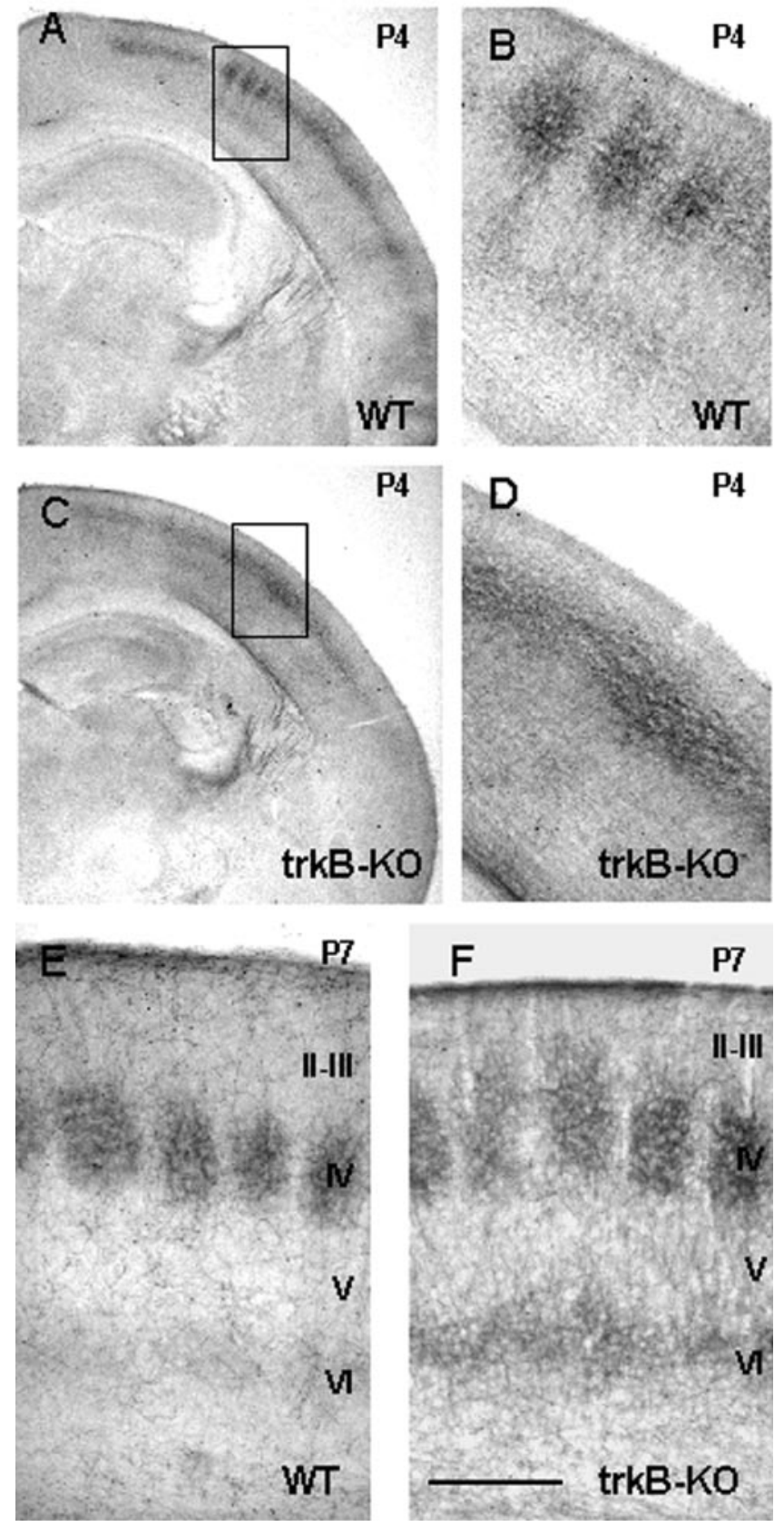

Figure 5. Comparison of the development of sensory thalamocortical axons in wild-type $(W T)(A, B, E)$ and trkB-KO $(C, D, F)$ pups at $\mathrm{P} 4$ $(A-D)$ and $\mathrm{P} 7(E, F)$ as revealed by SERT immunolabeling. $A, B$, Coronal sections showing barrel segregation in layer IV at P4. B, Higher magnification of barrels shown in the area outlined in $A$. Note that thalamocortical axons extend in layers II-III toward the pial surface. $C, D$, Coronal section showing a lack of segregation in layer IV at P4. D, Higher magnification of layer IV shown in the area outlined in C. E, In wild-type pups, at P7, SERT-IR labels individual barrels in S1. SERT-IR is mainly restricted to layer IV, with few SERT-IR branches extending radially in layer III. $F$, In trkB-KO pups, at P7, barrels are well individualized in layer IV, although the SERT-IR plexus extends abnormally in the upper layer III. $E, F$, Cortical layers are indicated. Scale bar: $A, C, 2$ $\mathrm{mm} ; B, D, 450 \mu \mathrm{m} ; E, F, 250 \mu \mathrm{m}$.

SERT-IR appeared as a uniform band in the neocortex without entering medially the motor cortex and laterally the limbic cortex. By $\mathrm{P} 4$, in MAOA-KO mice TCAs were mainly restricted to layer IV, whereas, in MAOA-trkB-DKO mice, TCAs appeared as a thick uniform band of staining extending radially from the lower layer IV to the pial surface (Fig. $6 C, D$ ). By $\mathrm{P} 7$, the segregation of the main 5-HT-immunolabeled cortical areas was evident in MAOA-KO mice (Fig. 6E), and a few barrels could be discerned in PMBSF (Fig. 4C). TCAs were mainly restricted to layer IV (Fig. $6 E$ ) and displayed the same organization as observed at P2 or P4. In MAOA-trkB-DKO mice, 5-HT-immunolabeled territories appeared as a continuous band, and TCAs extended widely into layers II-III well beyond the layer IV (defined by mGluR5IR; see below) (data not shown).

DiI tracing of TCAs of MAOA-trkB-DKO mice at P8 showed the nature and the morphology of the fibers (Fig. 7). In wild-type mice, TCAs were primarily confined in layer IV and the lower part of layer III, and very few TCAs extended in layer II or toward the pia (Fig. $7 A, B$ ). In MAOA-trkB-DKO mice, TCAs invaded massively layers II-III (Fig. 7C,D). Morphologically, TCAs in layers II-III displayed a poor degree of branching, and no growth cones could be observed (Fig. 7D). Occasionally, TCAs were seen in contact with the pial surface, turning along layers I-II (Fig. $7 C, D, G)$ and reentering the deeper cortical layers.

These results show that thalamocortical alterations are more severe in MAOA-trkB-DKO mice compared with MAOA-KO or trkB-KO mice in both the radial and tangential planes, indicating that, in normal conditions, TrkB signaling and 5-HT could act together in the segregation of TCAs in layer IV.

\section{Organization of the cortex in trkB-KO and $M A O A$-trkB-DKO mice}

Organization of cortical neurons. A barrel consists of a dense ring of granular neurons (spiny stellate) arranged in a cylindricalshaped aggregate. Each barrel surrounds an area of low cell density, the hollow, and individual barrels are separated by septae (Fig. 8A). This cytoarchitectonic differentiation occurs normally in trkB-KO mice (Fig. $8 B$ ). In contrast, MAOA-trkB-DKO mice display similar cortical alterations to those described previously in MAOA-KO mice (Fig. 8C,D). The granular cells in layer IV do not cluster into barrels but instead form a continuous band with a homogeneous density (Cases et al., 1996). In $60 \%$ of MAOA-KO mice with a mixed background $(n=10)$, barrel-like structures were observed in the PMBSF (Fig. 8C) (Salichon et al., 2001). This was never seen in MAOA-trkB-DKO mice $(n=8)$, suggesting that cytoarchitectonic alterations were more severe than in MAOA-KO mice (Fig. 8D).

We used mGluR5-IR to identify a presence and a physiological differentiation of layer IV in MAOA-trkB-DKO mice. mGluR5-IR has been shown to be enriched in barrel centers and to be localized in the neuropil and on the surface of cell bodies and dendrites in layer IV (Blue et al., 1997; Munoz et al., 1999). At P7, mGluR5-IR was organized in barrels in both wild-type (Munoz et al., 1999) (data not shown) and trkB-KO (data not shown) mice, whereas, in MAOA-KO mice (data not shown), mGluR5-IR formed a uniform band, suggesting that the segregation of dendrites in barrels is altered. In MAOA-trkB-DKO mice, mGluR5-IR displayed a similar uniform organization restricted radially to layer IV, allowing us to precisely localize layer IV (data not shown).

\section{Organization of the subcortical stations}

Previous studies have shown that the subcortical stations of the somatosensory system, the barrelettes in the brainstem and the barrelloids in the ventrobasal thalamic nucleus, display no major alterations in MAOA-KO mice (Cases et al., 1996), although subtle alterations were reported in the representation 


\section{MAOA-KO}
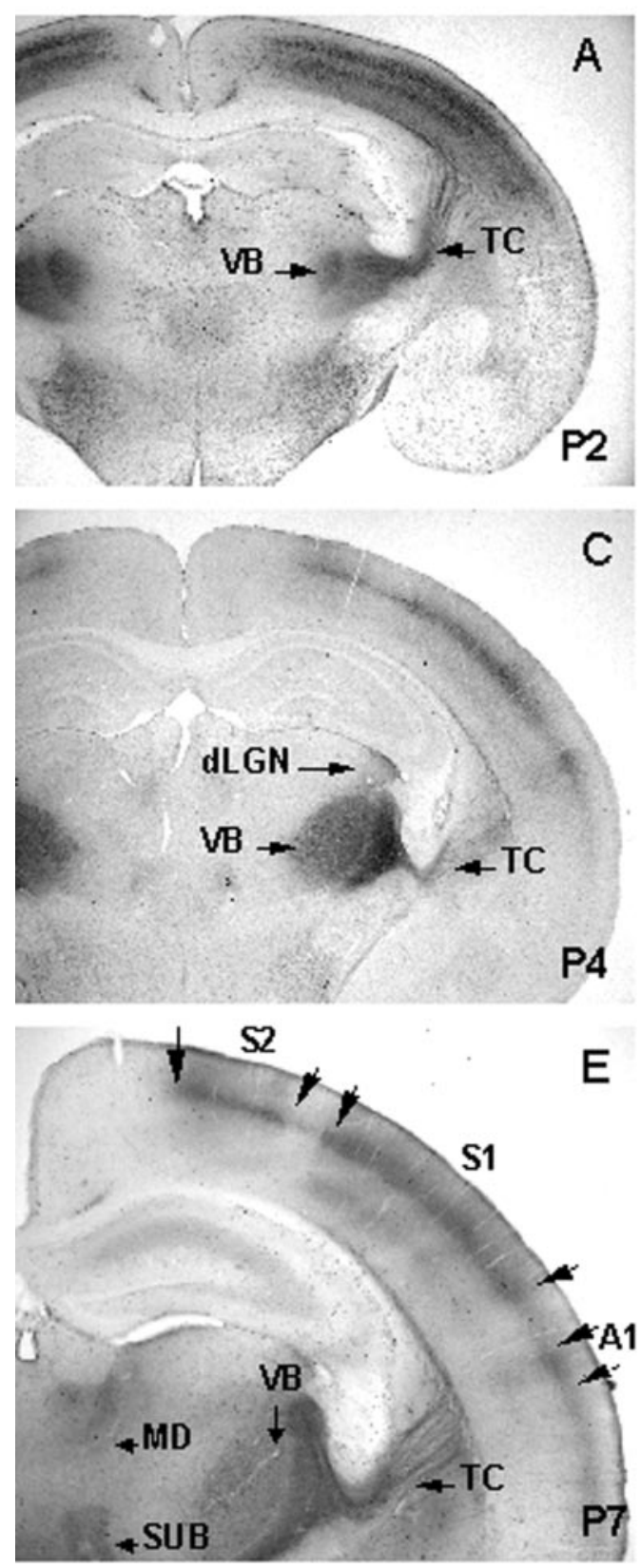

\section{MAOA-trkB-DKO}
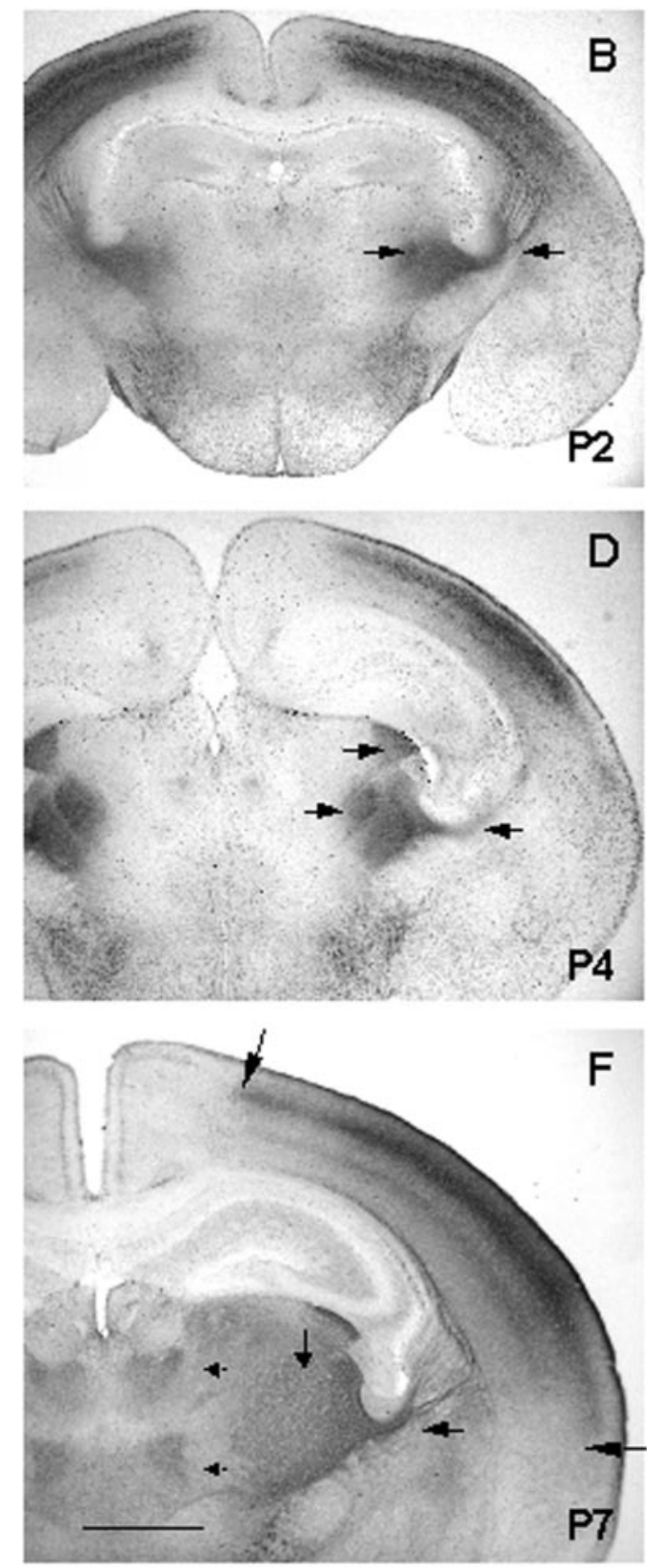

Figure 6. Comparison of the development of sensory thalamocortical axons in MAOA-KO $(A, C, E)$ and MAOA-trkB-DKO $(B, D, F)$ pups at $\mathrm{P} 2, \mathrm{P} 4$, and $\mathrm{P} 7$ as revealed by 5-HT-IR. $A, B$, Coronal sections of MAOA-KO $(A)$ and MAOA-trkB-DKO $(B)$ pups at P2 showing a similar pattern of 5-HT-IR. Note the very dense immunolabeling in the developing cortical plate. $C, D$, Coronal sections of MAOA-KO $(C)$ and MAOA-trkB-DKO $(D)$ pups at P4 showing an abnormal organization of 5-HT-IR in MAOA-trkB-DKO mice. In MAOA-KO mice, 5-HT-IR is mainly restricted to layer IV. In MAOA-trkB-DKO mice, 5-HT-IR extends to the pial surface. $E, F$, Coronal sections of MAOA-KO $(E)$ and MAOA-trkB-DKO $(F)$ pups at P7. In MAOA-KO pups, 5-HT-IR is restricted to the presumptive locations of the HP and PMBSF representations and A1 (large arrows delineate these areas). Note also the cortical areas that do not display 5-HT-IR in layer IV. In layer VI, 5-HT-IR appears as a segmented band. In MAOA-trkB-DKO mice, the 5-HT-IR plexus appears as a continuous band of staining covering all neocortical areas, from HP (top arrow) to A1 (bottom arrow). Note also the fusion of 5-HT-IR plexuses in layer V I. $d L G N$, Dorsal lateral geniculate nucleus; $M D$, mediodorsal nucleus; $S U B$, submedial nucleus; $T C$, thalamocortical axons. Scale bar: $A, C, 2 \mathrm{~mm} ; B-F, 570 \mu \mathrm{m}$.

of the barreloids corresponding to the small whiskers (Salichon et al., 2001). Similarly, we detected no gross alterations in the organization of the barrelettes and the barreloids in MAOA$\mathrm{KO}$, trkB-KO, and MAOA-trkB-DKO mice using mGluR5-IR for the barrelettes and $\mathrm{CO}$ activity for the barreloids (Fig. 9).

\section{DISCUSSION}

We demonstrated that the aberrant tangential outgrowth of TCAs in layer IV of MAOA-KO mice does not require TrkB signaling because the combined disruption of $t r k B$ and MAOA does not rescue the MAOA phenotype. Instead, in MAOA-trkB- 

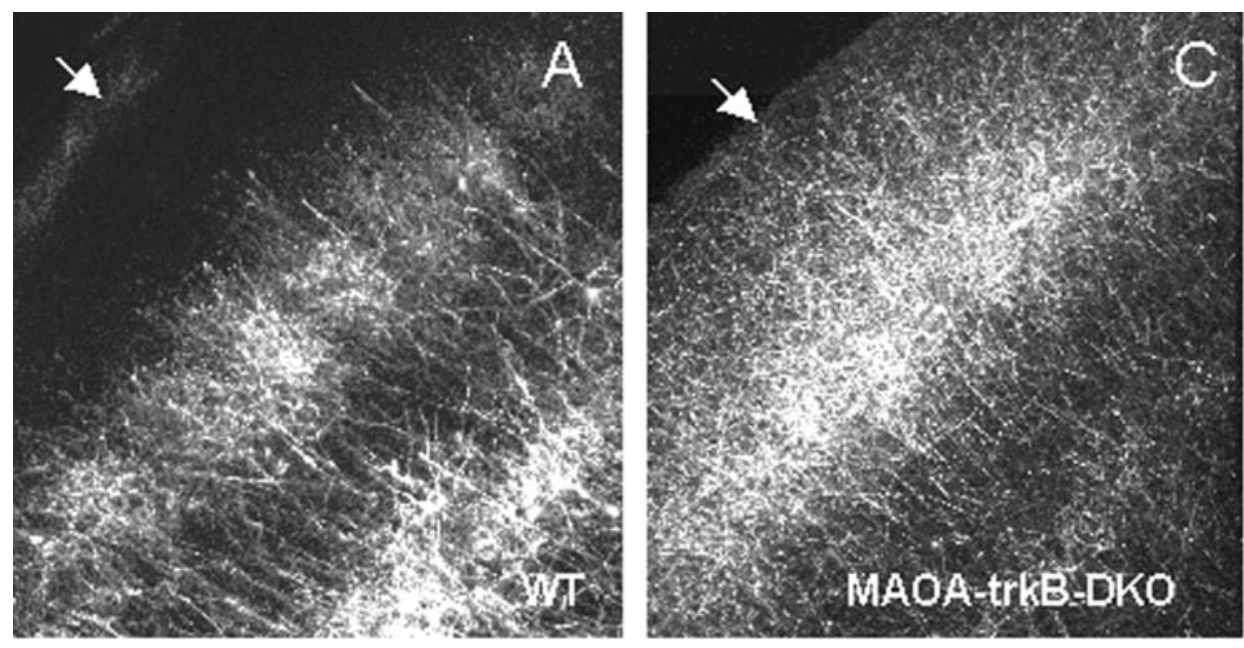

Figure 7. DiI tracing of thalamocortical axons in wild-type $(W T)(A, B, E)$ and MAOAtrkB-DKO $(C, D, F, G)$ pups at P8. $A, B$, In wild type, thalamocortical axons are clustered into barrels, and their terminals are mainly restricted to layer IV and do not massively extend in the supragranular layers. $B$, Higher magnification of $A$. $C, D, G$, In MAOA-trkB-DKO mice, thalamocortical axons densely innervate layer IV but also supragranular layers II-III. $D$, Higher magnification of $C$. $G$, Higher magnification of a section taken from another MAOA-trkBDKO pup. $D, G$, Small open arrows point to portions of axons that are oriented perpendicular to the pial surface. Small filled arrows point to portions of ectopic thalamocortical axons that are oriented parallel to the pial surface in layers I-III $(D, G) . A-D, G$, Large arrows indicate the pia. $E, F$, Bright-field photomicrographs of coronal sections showing the area of DiI diffusion in the thalamus of the wild-type pup $(E)$ and the MAOAtrkB-DKO pup $(F)$ shown in $A, B$ and $C, D$ respectively. These sections are $400 \mu \mathrm{m}$ rostral to the site of injections. Scale bar: $A, C$, $150 \mu \mathrm{m} ; B, D, G, 60 \mu \mathrm{m} ; E, F, 2 \mathrm{~mm}$.
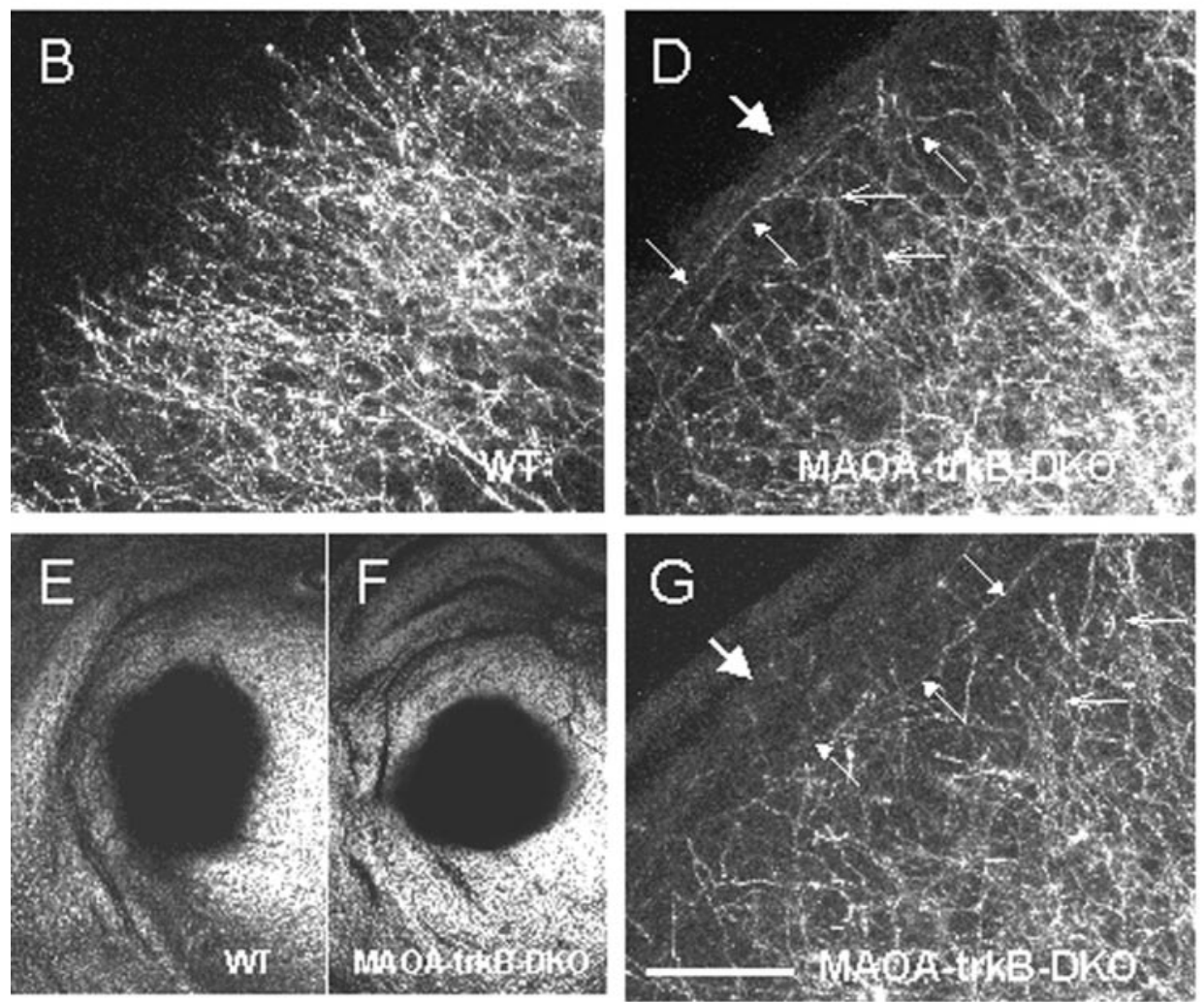

DKO mice, TCAs are more exuberant in both the tangential and radial planes and abnormally invade the supragranular cortical layers. In trkB-KO mice, TCAs innervate the supragranular layers, albeit to a lesser extent than in MAOA-trkB-DKO mice. These alterations are not secondary to an increased cortical cell death. In fact, cell death is reduced in MAOA-trkB-DKO mice compared with trkB-KO mice alone, suggesting a role for 5-HT in preventing apoptosis induced by trkB deficiency.

\section{The trophic effect of $5-\mathrm{HT}$ is not linked to TrkB signaling}

Increasing serotonin levels in the primary somatosensory cortex during early postnatal life by disruption of the MAOA gene prevents the clustering of both granular neurons and TCAs (Cases et al., 1995). Recent in vitro experiments indicate that 5-HT directly affects the growth of TCAs, increasing the length of the primary processes, increasing the total length of all processes, and increasing the number of branch points per cell and per primary neurite (Lieske et al., 1999). These effects on neurite outgrowth appear to be mediated by the 5-HT1B receptor subtype (Lotto et al., 1999). These results indicate that 5-HT could act as a trophic factor for TCA outgrowth.

Several findings have implicated TrkB signaling in cortical differentiation. Infusion of NT-4 or BDNF in the developing kitten visual system abolishes the segregation of TCAs, possibly by increasing their branching (Cabelli et al., 1995). In agreement with others, we find that $t r k B$ expression in TCAs and layer IV neurons correlates with the time at which TCAs and cortical neurons cluster into barrels. The similar effects of 5-HT excess and BDNF-NT-4 infusion on TCAs raise the possibility that 5-HT may positively regulate TrkB signaling and that ablation of trkB may ameliorate the MAOA phenotype. However, this does not occur. There is no difference in trkB expression patterns or in 

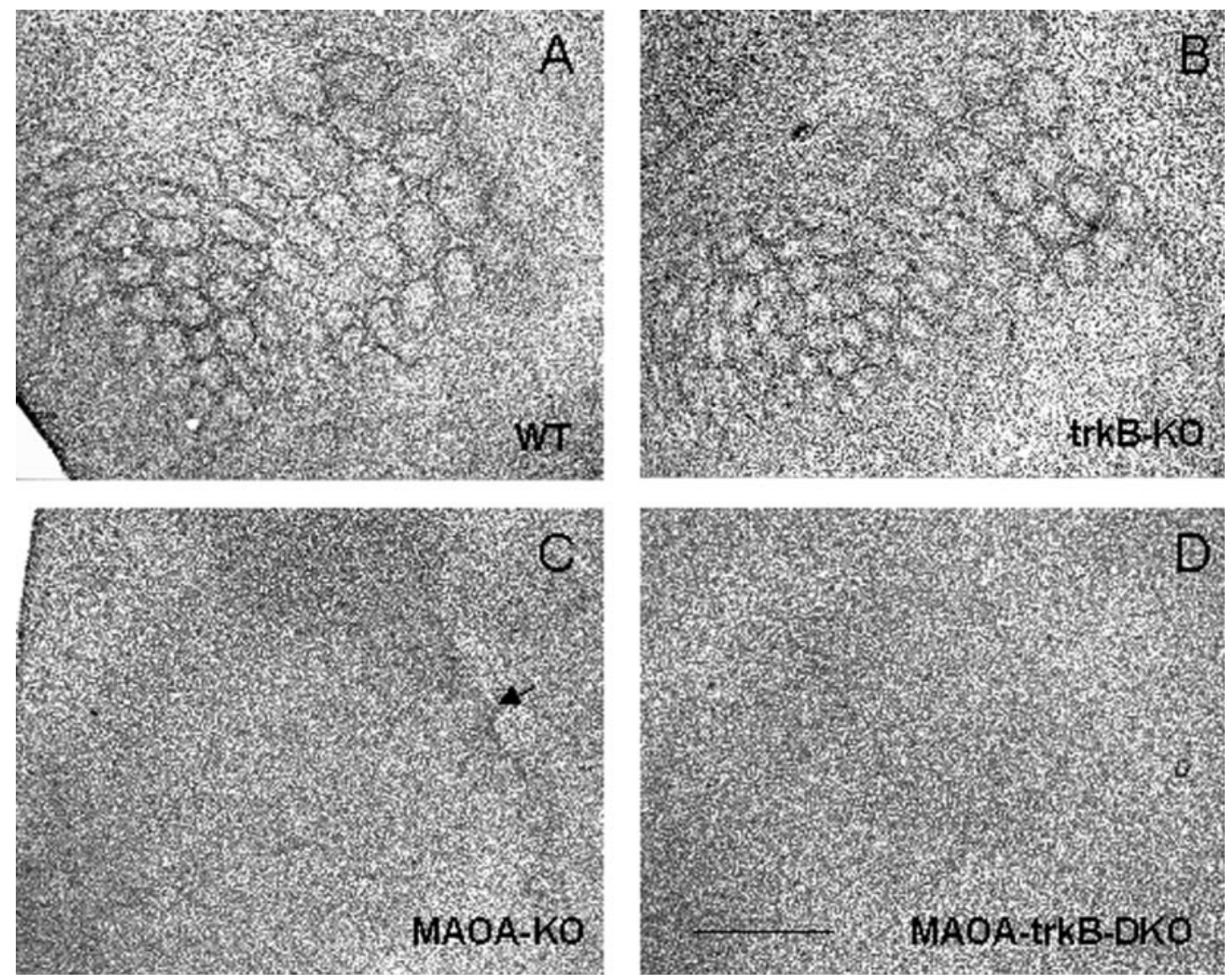

Figure 8. Segregation of granular neurons in wild-type $(A)$, trkB-KO $(B)$, MAOA-KO $(C)$, and MAOA-trkB-DKO $(D)$ mice at P9. $A$, Tangential section of a flattened cortex showing the clustering of granular neurons in PMBSF and AS of a wild-type pup. $B$, Normal segregation of granular neurons in PMBSF and AS in a trkB-KO pup. Note that barrels appear slightly smaller than in wild type $(A)$. $C$, Altered segregation of granular neurons in an MAOA-KO pup. Note a residual clustering of granular neurons in the region corresponding to the straddlers and the first arcs of the PMBSF. $D$, A complete lack of clustering of granular neurons is observed in MAOA-trkB-DKO mice. Scale bar, $1.2 \mathrm{~mm}$.

BDNF and NT-4 protein levels in the barrel cortex or the thalamus of MAOA-KO mice during the critical period. Hence, 5-HT does not influence TrkB signaling, and the trophic effect exerted by 5 -HT on TCAs does not require TrkB signaling.

\section{Analysis of trkB deficiency on the development of the somatosensory system}

\section{trkB deficiency on barrel neurons}

TrkB signaling is known to increase neuronal survival (Alcantara et al., 1997; Xu et al., 2000) and dendritic growth (Gates et al., 2000; Xu et al., 2000; Yacoubian and Lo, 2000) and to control the expression of LTP in developing cortical neurons (Sermasi et al., 2000). In agreement with Alcantara et al. (1997), we did not find an increase in cell death in layer IV of S1 in trkB-KO mice during the period of barrel formation. Furthermore, we confirm the normal topographic arrangement of granular neurons in trkBdeficient mice (Henderson et al., 1995). Gross analysis of the dendritic clustering of granular neurons using mGluR5 immunoreactivity (Blue et al., 1997; Munoz et al., 1999) demonstrates clear barrels from P5 to P7 in trkB-KO mice.

\section{trkB deficiency on periphery-related afferents}

TrkB is expressed by somatosensory thalamic neurons during the critical period for the refinement of TCAs (see above). It is possible therefore that, as suggested by Cabelli et al. (1995, 1997), limiting amount of cortical neurotrophins could act on TCAs to control their branching. By this hypothesis, the deletion of $t r k B$ could decrease the branching of TCAs and reduce barrel size, as observed in mice pharmacologically depleted of 5-HT (BennettClarke et al., 1994). However, 5-HT and SERT immunolabeling reveals normal TCAs clustering and normal cluster size in trkB-KO mice, confirming the findings of Henderson et al. (1995) that TrkB signaling is not necessary for overall barrel field mapping. However, we find that TCAs in trkB-KO mice abnormally extend into layers II-III, suggesting that TrkB signaling participates, at least to some extent, in restricting TCAs to layer IV.

The slowing, branching, and terminating of thalamic axons in layer IV implies that thalamic axons are influenced by molecules produced by the cortex. These molecules could be produced by layer IV neurons and attract TCAs and/or stabilize their synaptic contacts. Alternatively, supragranular layers may produce molecules that are repulsive for TCAs and/or not favorable for synaptic stabilization. Hence, several alternative hypotheses could be proposed for TrkB in establishing the laminar specificity of TCA terminations. First, TrkB signaling could control the elimination of exuberant branches, and deletion of $\operatorname{trk} B$ could stabilize an ectopic projection to layers II-III. In support of this hypothesis, TCAs extend in the supragranular layers in wild-type mice between P3 and P5 (Catalano et al., 1996) (Rebsam, Seif, and Gaspar, unpublished results).

Alternatively, TrkB signaling in layer IV could inhibit the outgrowth of TCAs in inappropriate layers of the cortex by either a direct inhibition of axon extension by TrkB in the supragranular 
Figure 9. Subcortical organization of the somatosensory pathway. Barreloids $(A-D)$ in the thalamus and barellets $(E-H)$ in the brainstem are visualized in wildtype $(W T)(A, E), \operatorname{trkB}-\mathrm{KO}(B, F)$, MAOA-KO $(C, G)$, and MAOA-trkB-DKO $(D, H)$ mice. $A-D$, Coronal sections of wild-type $(A)$, trkB-KO $(B)$, MAOA-KO $(C)$, and MAOA-trkB-DKO $(D)$ pups at $\mathrm{P} 9$ reacted for $\mathrm{CO}$ activity showing the organization of the barreloids in VB. Note that barreloids corresponding to the larger whiskers are well organized in each case. $E, F$, Coronal sections of wild-type $(E), \operatorname{trkB}-\mathrm{KO}(F)$, MAOA-KO $(G)$, and MAOA-trkB-DKO $(H)$ pups at P7. mGluR5-IR shows a normal organization of the barrelettes in the
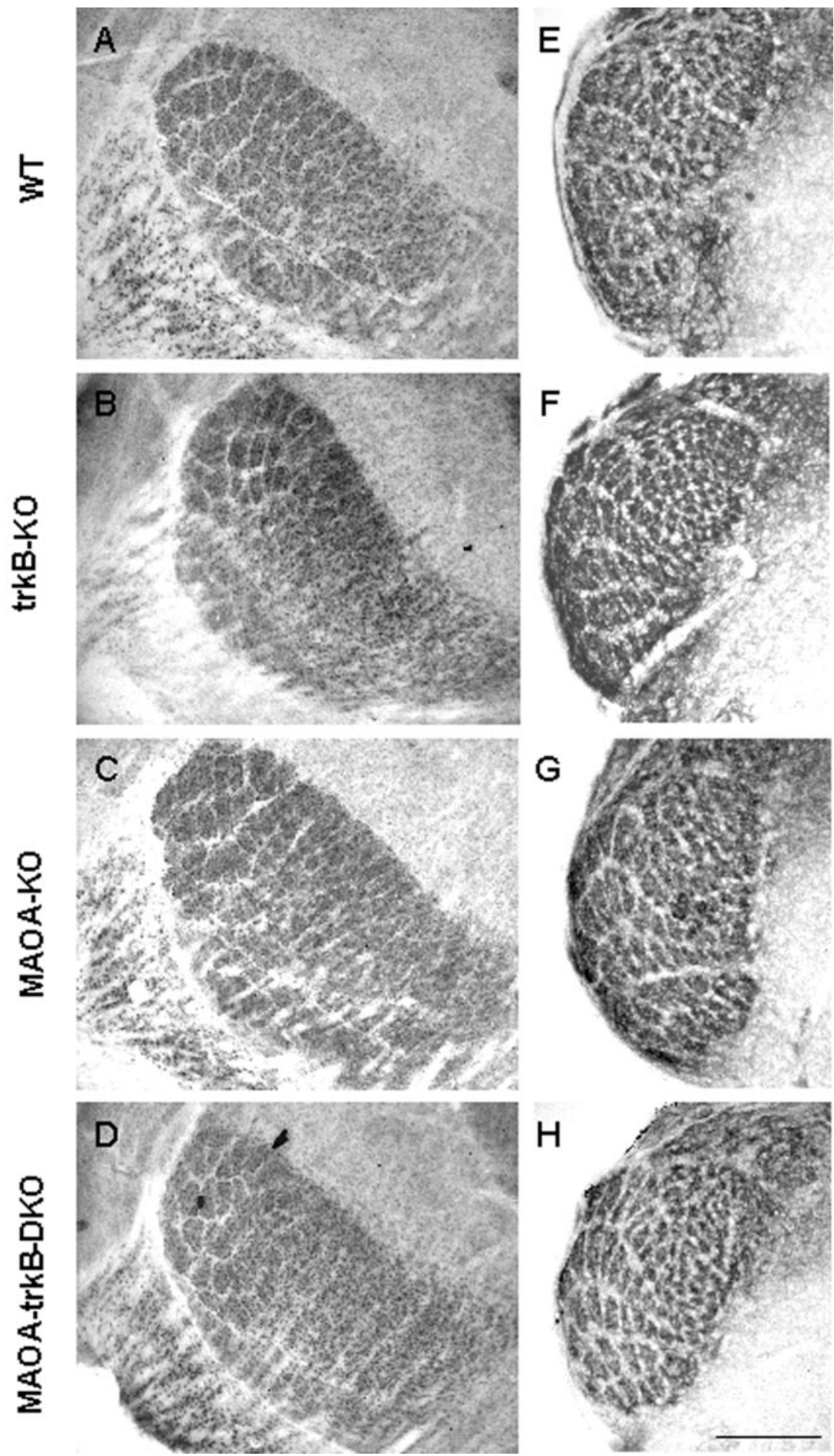
nucleus oralis. Scale bar, $0.2 \mathrm{~mm}$.

layers or promoting axon branching and synaptogenesis in layer IV. The high levels of TrkB in TCAs and layer IV neurons during the first postnatal week suggest that the latter possibility is more likely. In vitro experiments demonstrated that TCAs grow into cortical explants and terminate in layer IV, regardless of whether ingrowth is initiated from the pial surface or the white matter (Bolz et al., 1992; Molnar and Blakemore, 1995, 1999; Molnar et al., 1998). Furthermore, the selective depletion of layer IV neurons provokes a massive invasion of superficial cortical layers by
TCAs (Noctor et al., 2001; Palmer et al., 2001). These data strongly suggest the presence of a layer IV stop signal that positively regulates terminal branching and synaptogenesis of TCAs.

It is possible that, rather than being the stop signal itself, TrkB signaling induces molecules whose expression patterns determine TCA termination. Numerous adhesion molecules participate in the regulation of axon collapse and branching, including L1, neural cell adhesion molecule, cadherins, semaphorins, and ephrins (Hsueh and Sheng, 1998; Obst-Pernberg and Redies, 
1999; Chavis and Westbrook, 2001). Repulsive molecules of the semaphorin or ephrin family may delineate cortical territories through which thalamic axons grow, thereby influencing invasion by TCAs and their laminar specificity (Bagnard et al., 1996, 2001; Skaliora et al., 1998; Vanderhaeghen et al., 2000). Within these globally permissive zones, fibers could be further sequestered based on their sensitivities to other diffusible factors, cell surface molecules, or extracellular matrix cues. By this scenario, the expression of these trkB-inducible molecules may be altered in trkB-KO and MAOA-trkB-DKO mice, leading to a lack of refinement of TCAs in layer IV.

\section{Synergistic effect of excess 5-HT and lack of trkB}

MAOA-trkB-DKO mice show an exaggeration of both the MAOA-KO and the trkB-KO phenotypes. All primary and secondary sensory representations fuse, and there is a large increase in the density of TCA terminals in the superficial layers of MAOA-trkB-DKO mice. The mechanisms underlying these alterations are not known, and many suggestions could be proposed. However, perhaps the most likely is that 5-HT and TrkB act in concert to restrict the termination pattern of TCAs in the tangential and radial planes, respectively. 5-HT could act directly on TCAs, preventing their ability to respond to certain cortical cues, and TrkB may help delineate the cortical territory over which TCAs normally terminate. When either gene is removed by itself, the result is a more subtle alteration in the mapping of TCAs. When the two mutations are combined, the growing TCAs are free to invade a larger area of the cortex. Although this hypothesis can explain the increase in TCA termination in supragranular layers, it is not obvious why the various sensory areas should fuse in the MAOA-trkB-DKO mice. It would appear that the definition of areal boundaries by TCAs is under the control of numerous molecules, and compensation occurs if only one is ablated.

An alternative possibility for the synergistic effects of MAOA and trkB ablation is that cells normally producing the stop signals die in MAOA-trkB-DKO mice. We found a slight increase in cell death in layers II-III and IV in trkB-KO mice. In contrast, no increased cell death was observed in MAOA-trkB-DKO mice. This shows that excess 5-HT is able to rescue the increased cell death induced by $\operatorname{trk} B$ deficiency in the somatosensory cortex. Interestingly, this has also been observed in other discrete neuronal populations, such as the hippocampus or the cingulate cortex (T. Vitalis, unpublished results). Together, this suggests that 5-HT could have a neuroprotective effect on discrete neuronal populations.

\section{REFERENCES}

Agmon A, Yang LT, O'Dowd DK, Jones EG (1993) Organized growth of thalamocortical axons from the deep tier of terminations into layer IV of developing mouse barrel cortex. J Neurosci 13:5365-5382.

Agmon A, Yang LT, Jones EG, O'Dowd DK (1995) Topographical precision in the thalamic projection to neonatal mouse barrel cortex. J Neurosci 15:549-561.

Alcantara S, Frisen J, del Rio JA, Soriano E, Barbacid M, Silos-Santiago I (1997) TrkB signaling is required for postnatal survival of CNS neurons and protects hippocampal and motor neurons from axotomyinduced cell death. J Neurosci 17:3623-3633.

Alsina B, Vu T, Cohen-Cory S (2001) Visualizing synapse formation in arborizing optic axons in vivo: dynamics and modulation by BDNF. Nat Neurosci 4:1093-1101.

Bagnard D, Betz H, Gotz M, Puschel AW, Boltz J (1996) Do semaphorins act as guidance molecules for afferent and efferent projections in the developing cerebral cortex? Soc Neurosci Abstr 22:1473.

Bagnard D, Chounlamountri N, Puschel AW, Bolz J (2001) Axonal surface molecules act in combination with semaphorin 3 a during the establishment of corticothalamic projections. Cereb Cortex 11:278-285.
Bennett-Clarke CA, Leslie MJ, Lane RD, Rhoades RW (1994) Effects of serotonin depletion on vibrissa-related patterns of thalamic afferents in the rat's somatosensory cortex. J Neurosci 14:7594-7607.

Blue ME, Martin LJ, Brennan EM, Johnston MV (1997) Ontogeny of non-NMDA glutamate receptors in rat barrel field cortex. I. Metabotropic receptors. J Comp Neurol 386:16-28.

Bolz J, Novak N, Staiger V (1992) Formation of specific afferent connections in organotypic slice culture from rat visual cortex cocultured with lateral geniculate nucleus. J Neurosci 12:3054-3070.

Cabelli RJ, Hohn A, Shatz CJ (1995) Inhibition of ocular dominance column formation by infusion of NT4/5 or BDNF. Science 267:1662-1666.

Cabelli RJ, Shelton DL, Segal RA, Shatz CJ (1997) Blockade of endogenous ligands of trkB inhibits formation of ocular dominance columns. Neuron 19:63-76.

Cases O, Seif I, Grimsby J, Gaspar P, Chen K, Pournin S, Muller U, Aguet M, Babinet C, Shih JC, De Maeyer E (1995) Aggressive behavior and altered amounts of brain serotonin and norepinephrine in mice lacking MAOA. Science 268:1763-1766.

Cases O, Vitalis T, Seif I, De Maeyer E, Sotelo C, Gaspar P (1996) Lack of barrels in the somatosensory cortex of monoamine oxidase A-deficient mice: role of a serotonin excess during the critical period. Neuron 16:297-307.

Catalano SM, Robertson RT, Killackey HP (1996) Individual axon morphology and thalamocortical topography in developing rat somatosensory cortex. J Comp Neurol 367:36-53.

Chavis P, Westbrook G (2001) Integrins mediate functional pre- and postsynaptic maturation at a hippocampal synapse. Nature 411:317-321.

Cohen-Cory S (1999) BDNF modulates, but does not mediate, activitydependent branching and remodeling of optic axon arbors in vivo. J Neurosci 19:9996-10003.

Cohen-Cory S, Fraser SE (1995) Effects of brain-derived neurotrophic factor on optic axon branching and remodeling in vivo. Nature 378:192-196.

Das KP, Chao SL, White LD, Haines WT, Harry GJ, Tilson HA, Barone Jr S (2001) Differential patterns of nerve growth factor, brain-derived neurotrophic factor and neurotrophin-3 mRNA and protein levels in developing regions of rat brain. Neuroscience 103:739-761.

Fontaine P, Changeux JP (1989) Localization of nicotinic acetylcholine receptor alpha-subunit transcripts during myogenesis and motor endplate development in the chick. J Cell Biol 103:1025-1037.

Gates MA, Tai CC, Macklis JD (2000) Neocortical neurons lacking the protein-tyrosine kinase $\mathrm{B}$ receptor display abnormal differentiation and process elongation in vitro and in vivo. Neuroscience 98:437-447.

Hamon M, Fattaccini CM, Adrien J, Gallissot MC, Martin P, Gozlan H (1988) Alteration of central serotonin and dopamine turnover in rats treated with ipsapirone and other 5-hydroxytryptamine1A agonists with potential anxyolytic properties. J Pharmacol Exp Ther 246:745-752.

Hata Y, Oshshima M, Ichisaka S, Wakita M, Fukuda M, Tsumoto T (2000) Brain-derived neurotrophic factor expands ocular dominance columns in visual cortex in monocularly deprived and nondeprived kittens but does not in adult cats. J Neurosci 20:RC57(1-5).

Henderson TA, Mosconi TM, Foschini DR, Silos-Santiago I, Barbacid M, Jacquin MF (1995) Whisker-related patterning in the cerebral cortex of trkA, trkB, or trkC knock-out mice. Soc Neurosci Abstr 21:279.

Hsueh YP, Sheng M (1998) Eph receptors, ephrins, and PDZs gather in neuronal synapses. Neuron 21:1453-1463.

Itami C, Mizuno K, Kohno T, Nakamura S (2000) Brain-derived neurotrophic factor requirement for activity-dependent maturation of glutamatergic synapse in developing mouse somatosensory cortex. Brain Res 857:141-150.

Klein R, Smeyne RJ, Wurst W, Long LK, Auerbach BA, Joyner AL, Barbacid M (1993) Targeted disruption of the trkB neurotrophin receptor gene results in nervous system lesions and neonatal death. Cell 75:113-122.

Lebrand C, Cases O, Aldebrecht A, Doye A, Alvarez C, El Mestikawy S, Seif I, Gaspar P (1996) Transient uptake and storage of serotonin in developing thalamic neurons. Neuron 17:823-835.

Lebrand C, Cases O, Werhle R, Blakely RD, Edwards RH, Gaspar P (1998) Transient developmental expression of monoamine transporters in the rodent brain. J Comp Neurol 401:506-524.

Lieske V, Bennett-Clarke CA, Rhoades RW (1999) Effects of serotonin on neurite outgrowth from thalamic neurons in vitro. Neuroscience 90:967-974

Lotto B, Upton L, Price DJ, Gaspar P (1999) Serotonin receptor activation enhances neurite outgrowth of thalamic neurones in rodents. Neurosci Lett 269:87-90.

Masana Y, Wanaka A, Kato H, Asai T, Tohyama M (1993) Localization of trkB mRNA in postnatal brain development. J Neurosci Res 35:468-479.

Molnar Z, Blakemore C (1995) How do thalamic axons find their way to the cortex? Trends Neurosci 9:389-396.

Molnar Z, Blakemore C (1999) Development of signals influencing the growth and termination of thalamocortical axons in organotypic culture. Exp Neurol 156:363-393.

Molnar Z, Adams R, Blakemore C (1998) Mechanisms underlying the 
establishment of thalamocortical connections in the rat. J Neurosci 18:5723-5745.

Munoz A, Liu XB, Jones EG (1999) Development of metabotropic glutamate receptors from trigeminal nuclei to barrel cortex in postnatal mouse. J Comp Neurol 409:549-566.

Noctor SC, Palmer SL, McLaughlin DF, Juliano SL (2001) Disruption of layers 3 and 4 during development results in altered thalamocortical projections in ferret somatosensory cortex. J Neurosci 21:3184-3195.

Obst-Pernberg K, Redies C (1999) Cadherins and synaptic specificity. J Neurosci Res 38:130-138.

Palmer SL, Noctor SC, Jablonska B, Juliano SL (2001) Laminar specific alterations of thalamocortical projections in organotypic cultures following layer 4 disruption in ferret somatosensory cortex. Eur J Neurosci 13:1559-1571.

Pollock GS, Vernon E, Forbes ME, Yan Q, Ma Y-T, Hsieh T, Robichon R, Frost DO, Johnson JE (2001) Effects of early visual experience and diurnal rhythms on BDNF mRNA and protein levels in the visual system, hippocampus, and cerebellum. J Neurosci 21:3923-3931.

Rice FL, Van der Loos H (1977) Development of the barrels and barrel field in the somatosensory cortex of the mouse. J Comp Neurol 171:545-560.

Salichon N, Gaspar P, Upton L, Picaud S, Hanoun N, Hamon M, De Maeyer E, Murphy DL, Mossner R, Lesch KP, Hen R, Seif I (2001) Excessive activation of serotonin (5-HT) 1B receptors disrupts the formation of sensory maps in monoamine oxidase A and 5-HT transporter knock-out mice. J Neurosci 21:884-896.

Senft SL, Woolsey TA (1991) Growth of thalamic afferents into mouse barrel cortex. Cereb Cortex 1:308-335.

Sermasi E, Margotti E, Cattaneo A, Domenici L (2000) TrkB signalling controls LTP but not LTD expression in the developing rat visua cortex. Eur J Neurosci 12:1411-1419.

Singh TD, Mizuko K, Kohno T, Nakamura S (1997) BDNF and trkB mRNA expression in neurons of the neonatal mouse barrel field cortex: normal development and plasticity after cauterising facial vibrissae. Neurochem Res 7:791-797.

Skaliora I, Singer W, Betz H, Puschel AW (1998) Differential patterns of semaphorin expression in the developing rat brain. Eur J Neurosci 10:1215-1229.

Vanderhaeghen P, Lu O, Prakash N, Frisen J, Walsh CA, Frostig RD, Flanagan JG (2000) A mapping label required for normal scale of body representation in the cortex. Nat Neurosci 3:358-365.

Vitalis T, Cases O, Callebert J, Launay JM, Price DJ, Seif I, Gaspar P (1998) Effects of monoamine oxidase A inhibition on barrel formation in the mouse somatosensory cortex. Determination of a sensitive developmental period. J Comp Neurol 393:169-184.

Wong-Riley MTT, Welt C (1980) Histochemical changes in cytochrome oxidase of cortical barrels after vibrissal removal in neonatal and adult mice. Proc Natl Acad Sci USA 77:2333-2337.

Xu B, Zang K, Ruff NL, Zhang YA, McConnel SK, Stryker MP, Reichardt LF (2000) Cortical degeneration in the absence of neurotrophin signaling: dendritic retraction and neuronal loss after removal of the receptor TrkB. Neuron 26:233-245.

Yacoubian TA, Lo DC (2000) Truncated and full-length TrkB receptors regulate distinct modes of dendritic growth. Nat Neurosci 3:342-349.

Zetterstrom TS, Pei Q, Madhav TR, Coppell AL, Lewis L, GrahameSmith DG (1999) Manipulation of brain 5HT levels affect gene expression for BDNF in rat brain. Neuropharmacology 38:1063-1073. 